\title{
QUEEN'S
UNIVERSITY
BELFAST
}

\section{Benefits and Risks of Primary Treatments for High-risk Localized and Locally Advanced Prostate Cancer: An International Multidisciplinary Systematic Review}

\author{
Moris, L., Cumberbatch, M. G., Van den Broeck, T., Gandaglia, G., Fossati, N., Kelly, B., Pal, R., Briers, E.,
} Cornford, P., De Santis, M., Fanti, S., Gillessen, S., Grummet, J. P., Henry, A. M., Lam, T. B. L., Lardas, M., Liew, M., Mason, M. D., Omar, M. I., ... Wiegel, T. (2020). Benefits and Risks of Primary Treatments for High-risk Localized and Locally Advanced Prostate Cancer: An International Multidisciplinary Systematic Review.

European Urology, 77(5), 614-627. https://doi.org/10.1016/j.eururo.2020.01.033

Published in:

European Urology

Document Version:

Peer reviewed version

Queen's University Belfast - Research Portal:

Link to publication record in Queen's University Belfast Research Portal

\section{Publisher rights}

Copyright 2020 the authors.

This is an open access article published under a Creative Commons Attribution License (https://creativecommons.org/licenses/by/4.0/), which permits unrestricted use, distribution and reproduction in any medium, provided the author and source are cited.

\section{General rights}

Copyright for the publications made accessible via the Queen's University Belfast Research Portal is retained by the author(s) and / or other copyright owners and it is a condition of accessing these publications that users recognise and abide by the legal requirements associated with these rights.

\section{Take down policy}

The Research Portal is Queen's institutional repository that provides access to Queen's research output. Every effort has been made to ensure that content in the Research Portal does not infringe any person's rights, or applicable UK laws. If you discover content in the Research Portal that you believe breaches copyright or violates any law, please contact openaccess@qub.ac.uk. 


\section{European Urology}

BENEFITS AND RISKS OF PRIMARY TREATMENTS FOR HIGH-RISK LOCALIZED AND LOCALLY ADVANCED PROSTATE CANCER: An international multidisciplinary systematic review.

\section{--Manuscript Draft--}

Manuscript Number:

Article Type:

Section/Category:

Keywords:

\section{Corresponding Author:}

First Author:

Order of Authors:
EURUROL-D-19-00932R1

Review Paper

Prostate Cancer (PRO)

prostate cancer; Localized; Locally advanced; primary therapy; radical prostatectomy; External beam radiotherapy; brachytherapy; modality treatment; systemic treatment; Systematic review

Karin Plass, MA, Ph.D.

European Association of Urology

Arnhem, NETHERLANDS

Karin Plass, MA, Ph.D.

Karin Plass, MA, Ph.D.

Lisa Moris, M.D.

Marcus G Cumberbatach, M.D., Ph.D.

Thomas Van den Broeck, M.D., Ph.D.

Giorgio Gandaglia, M.D., Ph.D.

Nicola Fossati, M.D., Ph.D.

Brian Kelly, M.D., Ph.D.

Raj Pal, M.D., Ph.D.

Erik Briers, Bsc, Ph.D.

Philip Cornford, M.D., Ph.D.

Maria De Santis, M.D., Ph.D.

Stefano Fanti, M.D., Ph.D.

Silke Gillessen, M.D., Ph.D.

Jeremy P Grummet, M.D., Ph.D.

Ann M Henry, M.D., Ph.D.

Thomas B Lam, M.D., Ph.D.

Michael Lardas, M.D., Ph.D.

Matthew Liew, M.D., Ph.D.

Malcolm D Mason, M.D., Ph.D.

Imran M Omar, M.D., Ph.D.

Olivier Rouvière, M.D., Ph.D.

Ivo G Schoots, M.D., Ph.D.

Derya Tilki, M.D., Ph.D.

Roderick C van den Bergh, M.D., Ph.D.

Theodorus $\mathrm{H}$ van der Kwast, M.D., Ph.D.

Henk G van der Poel, M.D., Ph.D. 
Peter-Paul M Willemse, M.D., Ph.D.

Cathy Y Yuan, M.D., Ph.D.

Badrinath Konety, M.D., Ph.D.

Tanya Dorff, M.D., Ph.D.

Suneil Jain, M.D., Ph.D.

Nicolas Mottet, M.D., Ph.D.

Thomas Wiegel, M.D.,Ph.D.

\section{Abstract:}

Context. The optimal treatment for men with high-risk localized or locally advanced prostate cancer $(\mathrm{PCa})$ remains unknown.

Objective. To perform a systematic review of the existing literature on the effectiveness of the different primary treatment modalities for high-risk localized and locally advanced $\mathrm{PCa}$. The primary oncological outcome is the development of distant metastases at $\geq 5$ years of follow-up. Secondary oncological outcomes are prostate cancer specific mortality (PCSM), overall mortality (OM), biochemical recurrence and need for salvage treatment with $\geq 5$ years of follow-up. Non-oncological outcomes are quality of life (QoL), functional outcomes and treatment-related side effects reported.

Evidence acquisition. Medline, Medline In-Process, Embase, and the Cochrane Central Register of Randomized Controlled Trials were searched. All comparative (randomized and non-randomized) studies published between January 2000 and May 2019 with at least 50 participants in each arm were included. Studies reporting on high-risk localized PCa (ISUP grade 4-5 [GS 8-10] or PSA $>20 \mathrm{ng} / \mathrm{mL}$ or $\geq \mathrm{cT2} 2$ ) and/or locally advanced PCa (any PSA, cT3-4 or cN+, any ISUP grade/ GS score) or where subanalyses were performed on either group were included. The following primary local treatments were mandated: radical prostatectomy (RP), external beam radiotherapy (EBRT) ( $\geq 64 \mathrm{~Gy}$ ), brachytherapy $(\mathrm{BT})$ or multimodality treatment combining any of the local treatments above (+/- any systemic treatment). Risk of Bias (RoB) and confounding factors were assessed for each study. A narrative synthesis was performed.

Evidence synthesis. Overall, 90 studies met the inclusion criteria. RoB and confounding factors revealed high RoB for selection, performance and detection bias and low RoB for correction of initial PSA and biopsy GS. When comparing RP to EBRT, retrospective series suggested an advantage for RP, although with a low level of evidence. Both RT and RP should be seen as part of a multimodal treatment plan with possible addition of (post-operative) RT and/or ADT respectively. High levels of evidence exist for EBRT treatment with several RCTs showing superior outcome for adding long-term ADT or BT to EBRT. No clear cut-off can be proposed for RT dose but higher RT doses by means of dose escalation schemes result in an improved biochemical control. Twenty studies reported data on QoL, with RP resulting mainly in GU toxicity and sexual dysfunction, and EBRT in bowel problems.

Conclusion. Based on the results of this systematic review, both RP as part of multimodal treatment and EBRT + long-term ADT can be recommended as primary treatment in high-risk and locally advanced PCa. For high-risk PCa, also EBRT + BT can be offered, despite more grade 3 toxicity. Interesting, for selected patients, e.g. with higher comorbidity, a shorter duration of ADT might be an option. For locally advanced $\mathrm{PCa}$, EBRT + BT shows promising result but still needs further validation. In this setting, it is important that patients are aware that the offered therapy will be most likely in the context a multimodality treatment plan. In particular, if radiation is used, the combination of local with systemic treatment provides the best outcome, provided the patient is fit enough to receive both. Until the results of the SPCG15 trial are known, the optimal local treatment remains a matter of debate. Patients should be at all-time fully informed about all available options and the likelihood of a multimodal approach including the potential side effects of both local and systemic treatment. 
Patient summary. We reviewed the literature to see whether the evidence from clinical studies would tell us the best way of curing men with aggressive PCa that had not spread to other parts of the body such as lymph glands or bones. Based on the results of this systematic review, there is good evidence that both surgery and radiation therapy are good treatment options, in terms of prolonging life and preserving QoL, provided they are combined with other treatments. In the case of surgery this means including RT, and in the case of RT this means either hormonal therapy or combined RT with BT.

Suggested Reviewers:

Opposed Reviewers: 


\section{BENEFITS AND RISKS OF PRIMARY TREATMENTS FOR HIGH-RISK LOCALIZED AND LOCALLY ADVANCED PROSTATE CANCER: An international} multidisciplinary systematic review.

Lisa Moris ${ }^{1,2^{*}}$, Marcus G. Cumberbatch ${ }^{3 *}$, Thomas Van den Broeck ${ }^{1}$, Giorgio Gandaglia ${ }^{4}$, Nicola Fossati ${ }^{4}$, Brian Kelly ${ }^{5}$, Raj Pal ${ }^{6}$, Erik Briers ${ }^{7}$, Philip Cornford ${ }^{8}$, Maria De Santis ${ }^{9}$, Stefano Fanti $^{10}$, Silke Gillessen ${ }^{11,12}$, Jeremy P. Grummet ${ }^{13}$, Ann M. Henry ${ }^{14}$, Thomas B.L. Lam ${ }^{15,19}$, Michael Lardas ${ }^{16}$, Matthew Liew ${ }^{17}$, Malcolm D. Mason ${ }^{18}$, Muhammad Imran Omar ${ }^{19}$, Olivier Rouvière ${ }^{20}$, Ivo G. Schoots ${ }^{21}$, Derya Tilki ${ }^{22,23}$, Roderick C.N. van den Bergh ${ }^{24}$, Theodorus H. van Der Kwast ${ }^{25}$, Henk G. van Der Poel ${ }^{26}$, Peter-Paul M. Willemse ${ }^{27}$, Cathy Y. Yuan ${ }^{28}$, Badrinath Konety ${ }^{29}$, Tanya Dorff $\mathrm{T}^{30-31}$, Suneil Jain ${ }^{32,33}$, Nicolas Mottet ${ }^{34}$, Thomas Wiegel ${ }^{35}$

\section{*Shared first authorship}

This systematic review was performed under the auspices of:

- The European Association of Urology Guidelines Office Board

- The European Association of Urology Prostate Cancer Guideline Panel

- The American Society of Clinical Oncology

${ }^{1}$ Department of Urology, University Hospitals Leuven, Leuven, Belgium;

${ }^{2}$ Laboratory of Molecular Endocrinology, KU Leuven, Leuven, Belgium;

${ }^{3}$ Academic Urology Unit, University of Sheffield, Sheffield, UK;

${ }^{4}$ Unit of Urology, Division of Oncology, Urological Research Institute, IRCCS Ospedale San Raffaele, Milan, Italy;

${ }^{5}$ Department of Urology, University Hospital Birmingham, Birmingham, UK;

${ }^{6}$ Bristol Urological Institute, Southmead Hospital, Bristol, UK;

${ }^{7}$ Patient Advocate, Hasselt, Belgium;

${ }^{8}$ Royal Liverpool and Broadgreen Hospitals NHS Trust, Liverpool, UK;

${ }^{9}$ Department of Urology, Charité University Hospital, Berlin, Germany;

${ }^{10}$ Department of Nuclear Medicine, Policlinico S. Orsola, University of Bologna, Italy;

${ }^{11}$ Department of Medical Oncology and Haematology, Cantonal Hospital St. Gallen, University of Bern, Bern, Switzerland;

${ }^{12}$ Division of Cancer Sciences, University of Manchester and The Christie, Manchester, UK;

${ }^{13}$ Department of Surgery, Central Clinical School, Monash University, Australia;

${ }^{14}$ Leeds Cancer Centre, St. James's University Hospital and University of Leeds, Leeds, UK;

${ }^{15}$ Department of Urology, Aberdeen Royal Infirmary, Aberdeen, UK;

${ }^{16}$ Department of Urology, Leto Hospital, Athens, Greece;

${ }^{17}$ Department of Urology, Wrightington, Wigan and Leigh NHS Foundation Trust, Wigan, UK;

${ }^{18}$ Division of Cancer \& Genetics, School of Medicine Cardiff University, Velindre Cancer Centre, Cardiff, UK;

${ }^{19}$ Academic Urology Unit, University of Aberdeen, Aberdeen, UK;

${ }^{20}$ Hospices Civils de Lyon, Department of Urinary and Vascular Imaging, Hôpital Edouard Herriot, Lyon, F69437, France; Université de Lyon, Université Lyon 1, Faculté de Médecine Lyon Est, Lyon, F-69003, France;

${ }^{21}$ Department of Radiology \& Nuclear Medicine, Erasmus MC University Medical Center, Rotterdam, The Netherlands;

${ }^{22}$ Martini-Klinik Prostate Cancer Center, University Hospital Hamburg-Eppendorf, Hamburg, Germany;

${ }^{23}$ Department of Urology, University Hospital Hamburg-Eppendorf, Hamburg, Germany;

${ }^{24}$ Department of Urology, Antonius Hospital, Utrecht, The Netherlands;

${ }^{25}$ Department of Pathology, Erasmus MC University Medical Center, Rotterdam, The Netherlands;

${ }^{26}$ Department of Urology, Netherlands Cancer Institute, Amsterdam, The Netherlands;

${ }^{27}$ Department of Oncological Urology, University Medical Center, Utrecht Cancer Center, Utrecht, The Netherlands;

${ }^{28}$ Department of Medicine, Health Science Centre, McMaster University, Hamilton, ON, Canada;

${ }^{29}$ University of Minnesota, Minneapolis, MN, 55455, USA; 
${ }^{30}$ Department of Medical Oncology and Developmental Therapeutics, City of Hope, Duarte (CA), USA:

${ }^{31}$ Department of Medicine, University of Southern California (USC) Keck School of Medicine and Norris Comprehensive Cancer Center (NCCC), Los Angeles (CA), USA;

${ }^{32}$ Centre for Cancer Research and Cell Biology, Queen's University Belfast, Northern Ireland Cancer Centre, Belfast Health and Social Care Trust, Lisburn Road, Belfast, UK

Northern Ireland Cancer Centre, Belfast Health and Social Care Trust, Lisburn Road, Belfast, UK;

${ }^{33}$ Centre for Cancer Research and Cell Biology, Queen's University of Belfast, Lisburn Road, Belfast, UK;

${ }^{34}$ Department of Urology, University Hospital, St. Etienne, France;

${ }^{35}$ Department of Radiation Oncology, University Hospital UIm, Germany.

\section{Corresponding author:}

Dr. Lisa Moris

Department of Urology, University Hospitals Leuven, Leuven, Belgium. Laboratory of Molecular Endocrinology, KU Leuven, Leuven, Belgium.

Phone: +32 474828087

Email: lisa.moris1506@gmail.com

Keywords: prostate cancer; localized; locally advanced; primary therapy; radical prostatectomy; external beam radiotherapy; brachytherapy; modality treatment; systemic treatment; systematic review

Word count abstract: 651 words

Word count body text: 4698 words 


\section{ABSTRACT}

Context. The optimal treatment for men with high-risk localized or locally advanced prostate cancer (PCa) remains unknown.

Objective. To perform a systematic review of the existing literature on the effectiveness of the different primary treatment modalities for high-risk localized and locally advanced PCa. The primary oncological outcome is the development of distant metastases at $\geq 5$ years of follow-up. Secondary oncological outcomes are prostate cancer specific mortality (PCSM), overall mortality (OM), biochemical recurrence and need for salvage treatment with $\geq 5$ years of follow-up. Non-oncological outcomes are quality of life (QoL), functional outcomes and treatment-related side effects reported.

Evidence acquisition. Medline, Medline In-Process, Embase, and the Cochrane Central Register of Randomized Controlled Trials were searched. All comparative (randomized and non-randomized) studies published between January 2000 and May 2019 with at least 50 participants in each arm were included. Studies reporting on highrisk localized PCa (ISUP grade 4-5 [GS 8-10] or PSA $>20 \mathrm{ng} / \mathrm{mL}$ or $\geq \mathrm{cT2c}$ ) and/or locally advanced PCa (any PSA, cT3-4 or cN+, any ISUP grade/ GS score) or where subanalyses were performed on either group were included. The following primary local treatments were mandated: radical prostatectomy (RP), external beam radiotherapy (EBRT) ( $\geq 64 \mathrm{~Gy}$ ), brachytherapy (BT) or multimodality treatment combining any of the local treatments above (+/- any systemic treatment). Risk of Bias (RoB) and confounding factors were assessed for each study. A narrative synthesis was performed.

Evidence synthesis. Overall, 90 studies met the inclusion criteria. RoB and confounding factors revealed high RoB for selection, performance and detection bias and low RoB for correction of initial PSA and biopsy GS. When comparing RP to EBRT, retrospective series suggested an advantage for RP, although with a low level of evidence. Both RT and RP should be seen as part of a multimodal treatment plan with possible addition of (post-operative) RT and/or ADT respectively. High levels of evidence exist for EBRT treatment with several RCTs showing superior outcome for adding long-term ADT or BT to EBRT. No clear cut-off can be proposed for RT dose but higher RT doses by means of dose escalation schemes result in an improved biochemical control. Twenty studies reported data on QoL, with RP resulting mainly in GU toxicity and sexual dysfunction, and EBRT in bowel problems.

Conclusion. Based on the results of this systematic review, both RP as part of multimodal treatment and EBRT + long-term ADT can be recommended as primary treatment in high-risk and locally advanced PCa. For high-risk $\mathrm{PCa}$, also EBRT + BT can be offered, despite more grade 3 toxicity. Interesting, for selected patients, e.g. with higher comorbidity, a shorter duration of ADT might be an option. For locally advanced PCa, EBRT + BT shows promising result but still needs further validation. In this setting, it is important that patients are aware that the offered therapy will be most likely in the context a multimodality treatment plan. In particular, if radiation is used, the combination of local with systemic treatment provides the best outcome, provided the patient is fit enough to receive both. Until the results of the SPCG15 trial are known, the optimal local treatment remains a matter of debate. Patients should be at all-time fully informed about all available options and the likelihood of a multimodal approach including the potential side effects of both local and systemic treatment.

Patient summary. We reviewed the literature to see whether the evidence from clinical studies would tell us the best way of curing men with aggressive PCa that had not spread to other parts of the body such as lymph glands or bones. Based on the results of this systematic review, there is good evidence that both surgery and radiation therapy are good treatment options, in terms of prolonging life and preserving QoL, provided they are combined with other treatments. In the case of surgery this means including RT, and in the case of RT this means either hormonal therapy or combined RT with BT. 


\section{INTRODUCTION}

Following the introduction of prostate cancer (PCa) screening there has been a rise in the number of men diagnosed with clinically non-metastatic PCa. Nevertheless, $17-31 \%$ of these men present with high-risk localized or locally advanced disease and need curative treatment [1] since ten- and fifteenyear PCa specific mortality rates, if untreated, remain $28.8 \%$ and $35.5 \%$ respectively[2]. Although curative treatment provides a survival benefit [3], there is still no consensus regarding the optimal treatment option. In general, different strategies combining local with systemic treatment seem to have to best result in this patient cohort. Extensive evidence on the benefit of local curative treatment to improve survival already exists and therefore, ADT alone should not be considered a valid treatment option in the setting of high-risk and locally advanced PCa [4-6]. Currently the EAU PCa Guidelines recommend either radical prostatectomy (RP) with extended pelvic lymph node dissection in a multimodal approach (with possible post-operative RT +/- ADT), or external beam radiation therapy (EBRT) to a dose of 76-78 Gy or EBRT with brachytherapy (BT) boost both with long-term ADT in men with a life expectancy of $\geq 10 \mathrm{yrs}$ [3]. Evidence on which treatment modality is best is still lacking and has led to experience- rather than evidence-based management of patients. The aim of this systematic review is to compare the available primary local curative treatment options for high-risk localized and locally advanced PCa at diagnosis.

\section{EVIDENCE ACQUISITION}

The review was conjointly commissioned and undertaken by the European Association of Urology (EAU) Prostate Cancer Guideline Panel and the American Society of Clinical Oncology (ASCO). The protocol for this review has been published online (http://www.crd.york.ac.uk/PROSPERO; CRD42017078862) [7]

Briefly, the review was performed according to Preferred Reporting Items for Systematic Reviews and Meta-analyses (PRISMA) guidelines [8] and methodology as detailed in the Cochrane Handbook [9] (Supplementary material 1 and 2). The study population was comprised of male patients with histologically proven high-risk localized PCa (ISUP grade 4-5 [GS 8-10] or PSA $>20 \mathrm{ng} / \mathrm{mL}$ or $\geq c$ T2c) or locally advanced PCa (any PSA, cT3-4 or cN+, any ISUP grade/ GS) [3]. The treatment options of interest included any primary local treatment with curative intent: RP, EBRT ( $\geq 64$ Gy), BT or multimodality treatment (defined as a combination of primary local treatments +/- systemic treatment). The primary outcome was distant metastasis-free survival (DMFS) [10], secondary oncological outcomes included PCa-specific mortality (PCSM), overall mortality (OM), biochemical failure (BF) and need for salvage treatment. Secondary non-oncological outcomes were QoL, functional outcomes, and adverse events. Abstracts and full-text screening and data extraction were 
independently performed in duplicate (LM, MC, GG, NF, BK and RP) and disagreement was resolved by discussion or reference to an independent third party (TVDB). Due to the anticipated heterogeneity across studies, only a narrative synthesis was planned.

\section{EVIDENCE SYNTHESIS}

\section{Quantity of evidence identified}

The study selection process is outlined in the PRISMA flow diagram (Fig. 1). Ninety studies met the inclusion criteria, recruiting 367,347 patients with a total of 24 RCTs [11-34] and 66 non-randomized studies (NRS, - 4 prospective and 62 retrospective).

\section{Characteristics of the included studies}

Four major comparisons could be categorized: 1. Comparison of RP and RT (258,809 patients, all NRS), 2. Comparisons of RT with or without ADT and ADT duration (21,353 patients, 12 RCTs, 6 NRS), 3. Comparisons of different schedules of RT (77,152 patients, 11 RCT, 24 NRS), and 4. Comparison of RP with or without additional therapies (10,033 patients, 1 RCTs, 7 NRS). Both baseline study characteristics (supplementary tables 1-4) and corresponding outcome data (supplementary table 58) are presented. Table 1 and 5 summarize studies comparing RT with RP [35-64]. Table 2 and 6 report on studies comparing RT with or without ADT and ADT duration [13-18,23,26,27,29,30,32,6569]. Table 3 and 7 compare different RT modalities (including BT) [11,12,19-22,24,25,28,33,34,6992] and table 4 and 8 compare different RP modalities [16,31,93-98]. A separate table was created for studies reporting on RT with doses below 70Gy (supplementary table 9-10).

\section{Risk of bias and confounding assessment}

Figure 2 and 3 summarize the RoB assessment of all studies individually. In total, 24 RCTs were included, but in most RCTs, adequate blinding was not feasible. Therefore, as with all studies of this sort, selection, performance and detection bias overall are judged to be high on purely technical grounds. Attrition and reporting bias were judged to be low. Most confounding factors, like clinical T category, biopsy Gleason score and initial PSA were adequately considered through statistical adjustments in a large proportion of studies, whilst the correction for biopsy strategy remained unclear.

\section{EVIDENCE SYNTHESIS}

\section{Radical Prostatectomy versus Radiotherapy}


Thirty studies compared RP with EBRT (+/- ADT) [35-64]. All were NRS and there were no full-text RCTs available. There was only one prospective observational study [53]. Therefore, data quality in all of these reports is low. RT was delivered as monotherapy (or the use of ADT was not documented) in $11 / 30$ studies, and doses were $<70$ Gy in $4 / 30$ studies $[38,41,43-45,49,53,54,59,61,63]$. Less than $50 \%$ of the studies included adjuvant/salvage treatment after RP. Therefore, many of the studies in this category do not reflect contemporary practice.

\section{Oncological outcomes}

Four NRS reported on DMFS $[35,36,46,55]$ with no statistical difference between RP and EBRT + ADT. Twenty-seven out of 30 NRS described data on OM or PSCM, in favor of RP in the majority of the studies $[35,36,43,44,47,49,51,55,59,60,64]$. When comparing RP to the combination of EBRT + ADT, the reported benefit in OS and cancer-specific survival (CSS) ranged from $10 \%$ to $28 \%[35,55,60]$ and $4 \%$ to $8 \%[35,47,51,55]$ respectively at $10 \mathrm{yrs}$ favoring $\mathrm{RP}$, even when compared to recommended EBRT doses of $76-78$ Gy $[47,48,51]$. Of interest is the NRS by Tilki et al. evaluating RP in a multimodal setting. This study showed that RP without additional treatment compared to MaxRT (EBRT + BT + ADT), resulted in higher PCSM and OM rates (PCSM: HR: 2.80 [95\% $\mathrm{Cl}, 1.26-6.22]$ and all-cause mortality: HR 1.65 [95\% Cl, 0.94-2.91]) [40]. However, when compared to RP + adjuvant RT and/or $\operatorname{maxRP}(R P+R T+A D T)$, no differences in outcomes were observed.

\section{Non-oncological outcomes}

Regarding toxicity after RP or RT, two studies for locally advanced $[49,62]$ and three for high-risk PCa $[47,53,56]$ reported on genitourinary (GU) toxicity (i.e. need for catheterization, GU infection, hematuria, strictures, LUTS), sexual dysfunction and gastrointestinal (GI) toxicity (i.e. diarrhea, bleeding, proctitis). Despite very heterogeneous methods of reporting, studies showed generally more sexual dysfunction and urinary incontinence in patients after $\operatorname{RP}[53,56]$ and more GI toxicity after RT [47], which resembles the conclusions of the PROTECT-trial [99]

\section{Radical Prostatectomy - with or without additional therapy}

Eight studies compared different RP modalities [16,31,93-98], of which only one was a RCT [31], comparing salvage with adjuvant RT after RP in a high-risk PCa population.

\section{Oncological outcomes}

Two of the included studies evaluated the effect of adjuvant RT (vs salvage RT) on survival outcomes. $[31,97]$. The RCT by Bolla et al. only demonstrated an improvement in BFFS after adjuvant RT, with no difference in OS or PCSS [31]. 
Four studies reported on the combination of RP with systemic therapy $[16,93,94,96]$. One RCT reported on adjuvant bicalutamide after RP, but did not show an OS or CSS benefit after a median FU of $11.2 \mathrm{yrs}$ [16]. Two studies investigated the effect of neoadjuvant systemic treatments [93,94]. One NRS reported additional benefit of both BFFS and OS after 10 yrs of FU with neoadjuvant ADT [94]. The second NRS compared neoadjuvant LHRH analogue plus chemotherapy (estramustine, oral etoposide and paclitaxel [EEP]) before RP, showing an improved OM and BFFS [93]. However, FU of the combination arm was only 48.8 mo compared to 111 mo in the RP-arm.

\section{Non-oncological outcomes}

Only two studies reported functional outcome data. The RCT reported an increase in the 10-yr cumulative incidence of severe (grade 3$)$ toxicity $(p=0.052)$ and late grade $\geq 2$ GU toxicity $(p=0.003)$ with adjuvant RT, compared with salvage RT, while late GI toxicity did not differ between the two groups [31]. Sooriakumaran et al. compared the effect of open vs robotic RP on erectile function recovery in high-risk PCa patients showing no statistically significant difference after 24 mo of FU [98].

\section{EBRT with or without ADT and comparison of ADT duration EBRT alone vs EBRT + ADT}

Nine studies compared EBRT alone with EBRT + ADT, including 4 RCTs (and the updated results of EORTC 22863 trial) $[14,16,26,30,32]$ and 4 NRS $[65,66,68]$, plus one subanalysis of two RCTs, the RTOG 85-31 and RTOG 86-10 [67]. The EORTC 22863 and TROG 96.01 trial used LHRH agonists with an AR antagonist for flare-prevention [14,30,32]. Two other RCTs compared EBRT +/- adjuvant bicalutamide $[16,26]$.

There was fairly consistent evidence from the RCTs of benefits with combined EBRT+ADT, compared with EBRT alone. Although different RCTs reported on different outcomes, oncological outcomes were uniformly in favor of the combination EBRT+ADT. Three RCTs showed improvements in OS [16,26,30,32], PCSS in 2 studies [14,30,32] and DMFS in 1 study [32]. The subanalysis by Horwitz et al. of both RTOG 85-31 and RTOG 86-10 trials, excluding post-RP and CN1 patients, confirmed these beneficial findings for PCSS and DFMS [67].

Iversen et al. evaluated side effects associated with bicalutamide treatment in patients treated with RP or RT [16]. Most frequently reported side effects were gynecomastia (68.8\% vs $8.3 \%$ ) and mastalgia (73.7\% vs $7.6 \%$ ) in the bicalutamide group which was similar to previously reported data. There were no differences in other non-oncological outcomes between the randomised groups. 


\section{Studies of duration of ADT in the context of EBRT}

Eight studies evaluated the impact of ADT duration on oncological outcomes. For the comparison of short-term (4-6 months) vs long-term (24-36 months) ADT, 7 RCTs $[13,15,17,18,23,27,29]$ and 1 NRS [69] were identified. Intermediate-term ADT was defined as ADT for 18 mo.

An advantage for long-term ADT over short-term ADT was found in 4 RCTs with improvements in OM, PCSM and BF $[15,17,27,29]$. Two RCTs reported on the development of DM both showing a significant advantage for long-term ADT $[13,17]$. Of interest is the RCT by Nabid et al. showing no differences in OS, CSS and DFS between long-term ADT (36 mo) and intermediate ADT [18].

Only two studies reported on functional outcomes $[17,18]$. Nabid et al. showed no statistical difference in global QoL, however a clear difference in favor of intermediate ADT was observed for physical QoL $(p<0.001)$, fatigue $(p=0.003)$, nausea and vomiting $(p=0.04)$, constipation $(p=0.03)$, sexual activity and function $(p<0.001$ and $p=0.03)$ and specific treatment-related $Q o L(p<0.001)$ [18]. Lawton et al. reported no differences in late GU and GI toxicity comparing 4 mo and 24 mo of ADT [17].

\section{Radiotherapy- Different intertreatment modalities}

Thirty-five studies performed comparisons of different schedules, or combinations of modalities in the context of RT as the principal curative therapy [11,12,19-22,24,25,28,33,34,69-92]. The categories were EBRT vs EBRT + BT, EBRT/BT dose/fractionation/field size comparisons, and the addition of chemotherapy to RT as multimodality therapy.

\section{EBRT vs BT (monotherapy or BT boost + EBRT) (+/- ADT)}

There were 17 studies comparing EBRT to BT (monotherapy or as boost to EBRT) (+/- ADT) [20$22,69-72,74,76,77,82-87,92]$. Of these, there was one RCT [19,20,22], two prospective comparative studies [70,84], and 14 NRS. For monotherapy, EBRT doses ranged from 70 Gy to 81 Gy and LDR-BT from 140 Gy to $145 \mathrm{~Gy}[71,74,77,84,100]$. When combined with BT, EBRT doses varied between 40 to 50.4 Gy with BT doses for LDR-BT ranging from 90 to 115 Gy [20-22,76,82,83,87,92] and from 6.5 Gy in 3 fractions to $10 \mathrm{~Gy}$ in $2 \mathrm{~Gy}$ fractions for $\operatorname{HDR}-\mathrm{BT}[70,72,85,86]$.

Studies comparing EBRT with EBRT + BT boost showed an improvement in oncological outcomes in favor of combination therapy. The RCT (ASCENDE-RT) reported improved BFFS for EBRT + ADT with BT boost (83\%) compared to EBRT + ADT (73\%, p=0.048) at $6.5 \mathrm{yrs}$ FU [22]. In the NRS, EBRT + BT boost (+/-ADT) resulted in improved DMFS in only 1 study [83], OS in 5 studies, $[72,76,82,87,92]$, improved CSS in $4[72,76,83,86]$ and improved BFFS in 3 studies $[76,82,83]$ 
Five NRS compared BT alone (+/-ADT) to EBRT (+/- ADT) $[71,74,77,84,100]$. Three studies suggest improved BFFS and PCSM with BT compared to EBRT $[71,74,77]$. However, information on the administration of ADT or EBRT doses was often missing and patients receiving BT/EBRT tended to be younger and had a lower T-category. Of interest is the study by D'Amico et al. comparing BT (+/$A D T)$ with EBRT + BT (+/- ADT), showing that trimodality treatment (EBRT + BT + ADT) but not treatment with EBRT alone or ADT alone compared to BT, resulted in an improved PCSM [100].

Contrary to the superior oncological results for EBRT + BT (+/-ADT), data on QoL and side effects are less favorable. Three studies reported on higher GU toxicity after EBRT + BT boost $[20,21,85]$. In the ASCENDE-RT trial by Rodda et al., 5-yr grade 3 GU toxicity was worse when treated with EBRT + LDR-BT boost + ADT compared to dose-escalated EBRT + ADT (5-yr: 18.3\% vs. 5.2\% respectively) $[19,20]$. The NRS by Khor et al., showed more grade 3 strictures (as GU toxicity surrogate) in the combination group (5-yr: $11.8 \%$ vs $0.3 \%$ ) [85].

\section{EBRT - trials of dose, fractionation, and field size}

Seven RCTs $[11,12,19,24,25,34,88]$ and 11 NRS $[28,73,75,78-81,89-91]$ compared different EBRT modalities.

Four studies (2 different RCTs [and one update of the trial by Arcangeli et al] , 1 NRS) compared hypofractionation and conventional fractionation $[11,12,79,88]$, comparing conventional EBRT (78-80 Gy) to moderate hypofractionation (3.1 Gy fractions to a total dose of $62 \mathrm{~Gy}$ and 3.4 Gy fractions to a total dose of $64.6 \mathrm{~Gy})[11,12,88]$. There were no differences in DMFS, OM, PCSM or BFFS in any of these studies. Both RCTs reported on functional outcomes with no difference in the incidence and severity of late GI or GU toxicity [11] but an increase in overall grade 3 or worse late GU toxic effects (19\% vs 13\%) [88] after moderate hypofractionation compared to conventional EBRT was observed.

Eight studies compared different conventional EBRT doses ranging from 68 Gy to $>80$ Gy $[34,73,75,80,81,89,90,101]$, with increasing doses over the years due to the introduction of conformal and then intensity modulated RT (IMRT). One NRS compared 3D-conformal RT (70-74 Gy) to IMRT (78-82 Gy) showing better survival outcomes in the IMRT-group for BFFS, OS and CSS)[90].

Three studies evaluated the effect of pelvic irradiation in addition to EBRT, BT or both $[19,78,91]$. One RCT reported a significant improvement in PFS and BF for neoadjuvant ADT + wholepelvis RT when compared to neoadjuvant ADT + prostate-only RT or whole-pelvis RT + adjuvant EBRT [19]. A second RCT reported whole-pelvis RT to be associated with a significant improvement in BFFS in the EBRT + BT group but without impact on OS or PCSS [78].

\section{EBRT +/-chemotherapy}


Three studies reported on the addition of chemotherapy [24,25,33], with EEP in the RTOG 9902 trial and docetaxel in the QRT-SOGUG phase $2 \mathrm{~b}$ and RTOG 0521 trial $[25,33]$. The RTOG 0521 RCT showed improvement in OS with docetaxel compared to EBRT + ADT [24]. All trials reported a significantly higher rate of chemotherapy-related toxicities, especially in the RTOG 9902 trial which was closed early due to excess toxicity and treatment-related mortality.

\section{Locally advanced PCa}

Twelve studies reported specifically on locally advanced PCa (according to the EAU PCa guidelines definition), with 5 RCTs $[17,26,29,30,32]$ and 7 NRS $[43,49,56,57,62,65,67]$. Five NRS compared RP to EBRT +/- BT $[43,49,56,57,62]$, showing better survival outcomes for RP compared to EBRT +/- ADT in well selected patients. Four RCTs compared EBRT + ADT vs EBRT alone with outcomes in favor of the combination therapies (DMFS, OM, PCSM and/or BFFS) $[19,26,30,32]$. One NRS reported a reduced PCSM in patients treated with RT alone, however RT dose and ADT duration were not reported [65]. Finally, two RCTs compared EBRT + short-term ADT to EBRT + long-term ADT and showed superior DMFS for long-term ADT $[17,29]$.

\section{DISCUSSION}

\section{Principal findings}

\section{RP vs EBRT and RP intergroup comparison}

Historically, men with high-risk PCa have been managed most commonly with EBRT, ADT or both $[102,103]$, whilst RP has been discouraged in this setting, due to concerns about side effects and inadequate disease control [103-106]. The included retrospective studies report encouraging results for RP over EBRT with the advantage of avoiding ADT in many patients. However, no randomized data are available to evaluate RP vs EBRT +/- ADT in terms of survival outcomes and/or toxicity but the ongoing randomized SPCG-15 trial will provide us valuable information on this matter [107]. Clearly, the reported retrospective studies should be interpreted with extreme caution, as patients with good performance status and limited or no comorbidity may be more commonly considered for RP. Indeed, patients treated with RP in the included studies are younger with a less advanced tumor classification. Out of the 30 studies, 11 performed a propensity score matching for tumor and patient characteristics [38-40,43,49,51,56,59-62]. However, even this cannot completely correct for the inherent selection bias due to unmeasured confounding variables [108]. It is noteworthy that in several studies RP was compared with EBRT alone $[38,41,43-45,49,53,54,59,61,64]$ or EBRT $<70$ Gy $[37,41,55,57]$ which should be regarded as sub-optimal treatment in a contemporary high-risk setting. The same applies to RP monotherapy, which fails to be a definitive cure in many patients. 
Therefore, patients must be informed about the possible need for combination therapy (RP with RT alone and/or ADT). However, which therapeutic approach after RP is superior remains unclear [109].

We can conclude that:

- No curative primary treatment modality (as part of multimodality therapy) has shown superiority over any other curative treatment option in terms of survival.

- RP (including the option for [post-operative] radiotherapy and/or ADT) or EBRT+ADT can be offered to patients with high-risk localized and locally advanced PCa as part of multi-modal therapy.

\section{Studies in the context of primary radiotherapy}

Radiotherapy represents a valid treatment option but like RP, as part of a multimodal strategy in most cases $[14,16,26,30,32,67,68]$. Many of the included studies were performed in the era before dose-escalated RT and should be interpreted cautiously since they used RT doses far below the recommended 76-78 Gy - indeed, with 4 studies reporting doses below 70 Gy $[14,17,26,66]$. Extrapolating the findings of these studies to contemporary practice therefore requires much caution.

Five RCTs have confirmed the benefit of combining EBRT with ADT, and this is very well established treatment option in current practice. However, the optimal duration of ADT (from 18 mo to indefinite) remains undefined. In a high-risk setting, long-term ADT (18-36 mo) has shown clear benefits over short-term ADT $[17,29]$. This is not merely an effect of ADT compensating for lower doses of RT, since the RCT by Zapatero et al. confirmed that even with dose-escalated RT doses (median dose of $78 \mathrm{~Gy}$ ), long-term ADT (24 mo) results in longer BFFS and OS compared to 4 mo of ADT [27]. Due to significant side effects reducing ADT length seems desirable as long as it will not affect efficacy. Nabid et al. designed a superiority study comparing long-term ADT (36 mo) to intermediate ADT of 18 mo [18], showing no difference in DM, OS and CSS after 9.4 yrs FU but confirmed an improvement of certain QoL aspects (physical, emotional and social functioning and fatigue). Although the authors suggest that intermediate ADT might be non-inferior to 36 mo of ADT for OS, proper non-inferiority trials have to be performed before final recommendations can be made. Also, the use of RT doses of only $70 \mathrm{~Gy}$ and the low compliance of $53 \%$ to long-term ADT (vs. $88 \%$ for intermediate ADT) complicates interpretation of this study.

The combination of EBRT + BT boost aims to increase doses to the prostate whilst minimizing radiation to the surrounding organs. Only the ASCENDE-RT trial randomized patients to $46 \mathrm{~Gy}+\mathrm{EBRT}$ boost to a total of 78 Gy or to pelvic 46 Gy + LDR-BT boost and reported superior 9-yr BFFS rates of $62 \%$ to $83 \%$ respectively, despite a general increase in late GU-toxicity [20-22]. In multiple 
retrospective series this combination demonstrated excellent results with better local tumor control compared to EBRT alone. However, in most studies, patient and tumor characteristics were more favorable in the combination group with younger patients and lower clinical T-categories.

Hypofractionation has been developed to deliver equivalent biologically effective doses to the tumor with a higher dose per fraction; based on the fact that PCa cells are more sensitive to largedose fractions compared to the surrounding normal tissue. Both HDR-BT and EBRT schemes have tried to implement this but controversy remains. The RCTs by Arcangeli et al. and Incrocci et al. showed conflicting results in late complications, but equivalence $[11,12,88]$ in PCa deaths with moderate hypofractionation (62-64.6 Gy with 3.1-3.4 Gy per fraction) in high-risk PCa. From an economical and patient-friendly point of view, both moderate and extreme hypofractionation can offer great advantage with fewer fractions but further, well-designed non-inferiority trials are needed to confirm their role.

Data on the use of irradiation of the lymph nodes are limited in this SR and studies mostly report data for mixed patient groups (cNO-X)[19,78,91]. The RTOG 9413 trial showed a benefit of whole-pelvis RT with neoadjuvant ADT in high-risk PCa patients compared to prostate-only RT, highlighting the benefit of prophylactic pelvic RT and the interaction with hormonal therapy [19]. Two RCTs, RTOG 0924 and PIVOTAL-boost are in progress, which will compare whole-pelvis versus prostate-only RT and provide more information on hard clinical endpoints (such as OS) and the toxicity profile of whole-pelvis RT.

Finally, different trials evaluated the benefit of adding chemotherapy to curative local treatments with the aim of treating micro-metastatic disease. Optimizing chemotherapy regimens and time of delivery (neoadjuvant or adjuvant) remains experimental. The GETUG-12 trial suggested an improved relapse-free survival with docetaxel + ADT vs ADT alone [110]. The phase $2 b$ trial by Carles et al. reported good tolerability of low weekly doses of docetaxel, but without benefits in 5-yr BFFS, PFS and OS [33]. Its successor, the RTOG 0512 trial, revised treatment schedules with adapted RT schemes and docetaxel instead of EEP [24]. In a population with $84 \%$ GS 8-10 patients, an improvement in OS was observed with adjuvant docetaxel following RT after 5.7 yrs of FU. In contrast, the recently presented long-term results for MO high-risk PCa patients in the STAMPEDE trial did not show an improved OS with docetaxel before RT + long-term ADT[111]. However, upfront docetaxel did improve PFS and failure-free survival in this patient population without excess in late toxicity, which might influence future treatment decision making. An improved insight in patient profiles will be needed to identify those patients who will likely benefit from adjuvant chemotherapy. Other additional systemic therapy, including novel endocrine agents (like abiraterone acetate, apalutamide and enzalutamide) are currently being tested in clinical trials, combining systemic with 
local treatment for increased disease control, which is discussed to a fuller extend in a systematic review by Tosco et al. [112].

We can conclude that:

- In patients with localized high-risk or locally advanced disease, EBRT with long-term ADT (24$36 \mathrm{mo}$ ) +/- BT boost (HDR or LDR) are valid treatment options. ADT mostly consisted of a LHRH analogue combined with a one-month anti-androgen for flare prevention.

- Adjuvant ADT should be continued for at least $24 \mathrm{mo}$; however for all high-risk patients, there is insufficient evidence to support prolonging ADT for another year. Comorbidity at the time of diagnoses and treatment-related side effects must be taken into account when deciding on ADT duration.

- Although results are promising, there are not enough mature data to encourage the general use of adjuvant chemotherapy in the multimodality treatment of high-risk or locally advanced PCa. The recently presented data from the MRC STAMPEDE trial in high-risk MO patients will add greatly to the current knowledge [111].

Finally, our SR evaluated the effects of local treatment on QoL. In general, both radical and systemic treatments result in significant side effects, which affect QoL of patients and their families who are confronted with the diagnosis. We can conclude that patients treated with RP experience mainly GU toxicity and sexual dysfunction, while EBRT can result in GI problems. Attention should be drawn to these side effects and proper support should be organized.

\section{Implications for clinical practice and further research}

Patients with high-risk localized or locally advanced PCa frequently have recurrence driven by subclinical metastases and microscopic local tumor extension. Further optimization of treatment will therefore rely on improvement of multimodality treatment and development of novel therapeutic strategies. However, not only treatment but also classification of patients into prognostic groups is key for an optimal treatment. A recent SR on the impact of BCR after treatment with curative intent proposed an additional risk-stratification (EAU high-risk BCR and EAU low-risk BCR) based on risk factors for clinical progression and worse survival (short PSA-DT and a high final GS after RP, and high biopsy GS and a short interval to BCR after RT). Such a classification system can guide clinical decisions to initiate salvage treatment. A first validation of this classification system was performed in a large series of patients with BCR after RP, showing its potential and applicability in daily practice [113]. However, further validation is still mandatory in both post-RP and post-RT settings. Another 
rapidly evolving area is the use of (non-) genomic biomarkers and molecular imaging [114-117]. Such prognostic and predictive tools offer an alternative way of patient stratification supplementary to our clinical system and may guide clinicians in the decision whether to intensify follow-up and treatment schemes.

\section{Limitations and strengths of this systematic review}

This study represents the first SR comparing both oncological effectiveness and functional outcomes focusing on local treatment in high-risk and locally advanced PCa. This review was performed based on robust methodological standards and as a collaborate project involving two multidisciplinary panels of experts (EAU Prostate Cancer Guidelines Panel and ASCO) including a patient representative $[8,9,118]$. Limitations include the retrospective nature of the majority of studies, and the overall clinical and methodological differences between studies, contributing to the heterogeneity of data. Variation was apparent in baseline patient characteristics, type, duration and correct administration of ADT as well as the variety in RT doses. These inter-study differences limit direct comparison of data and preclude further strong or new recommendations. Ongoing big data projects, such as PIONEER and ICECaP, will define validated core outcome sets for both localized and metastatic PCa which should be used in future clinical trials [119]. Finally, clinical staging and stratification depended on standard imaging techniques with chest radiograph, abdominal CT and isotope bone scan in all included RCTs. However, the field of imaging and staging is rapidly evolving, with promising data for mpMRI, PET/CT and PSMA PET/CT for local staging and detection of lymph node and bone metastases. Results from current trials will enlighten us on the use and benefit of these new modalities for the management of high-risk and locally advanced PCa.

\section{CONCLUSION}

In this collaborative systematic review performed under the auspices of the EAU Prostate Cancer Guideline Panel and ASCO, we evaluated current evidence on the effectiveness of local primary therapy in high-risk and locally advanced PCa. Based on the results of this systematic review, both RP as part of multimodal treatment and EBRT + long-term ADT can be recommended as primary treatment in high-risk and locally advanced PCa. For high-risk PCa, also EBRT + BT can be offered, despite more grade 3 toxicity. Interesting, for selected patients, e.g. with higher comorbidity, a shorter duration of ADT might be an option. For locally advanced PCa, EBRT + BT shows promising result but still needs further validation. In this setting, it is important that patients are aware that the offered therapy will be most likely in the context a multimodality treatment plan. In particular, if radiation is used, the combination of local with systemic treatment provides the best outcome, 
provided the patient is fit enough to receive both. Until the results of the SPCG15 trial are known, the optimal local treatment remains a matter of debate. Patients should be at all-time fully informed about all available options and the likelihood of a multimodal approach including the potential side effects of both local and systemic treatment.

\section{REFERENCES}

[1] Cooperberg MR, Cowan J, Broering JM, Carroll PR. High-risk prostate cancer in the United States, 19902007. World J Urol 2008;26:211-218. doi:10.1007/s00345-008-0250-7.

[2] Rider JR, Sandin F, Andrén O, Wiklund P, Hugosson J, Stattin P. Long-term outcomes among noncuratively treated men according to prostate cancer risk category in a nationwide, populationbased study. Eur Urol 2013;63:88-96. doi:10.1016/j.eururo.2012.08.001.

[3] Mottet N, Bellmunt J, Bolla M, Briers E, Cumberbatch MG, De Santis M, et al. EAU-ESTRO-SIOG Guidelines on Prostate Cancer. Part 1: Screening, Diagnosis, and Local Treatment with Curative Intent. Eur Urol 2017;71:618-29. doi:10.1016/j.eururo.2016.08.003.

[4] Fosså SD, Wiklund F, Klepp O, Angelsen A, Solberg A, Damber JE, et al. Ten- and 15-yr Prostate Cancerspecific Mortality in Patients with Nonmetastatic Locally Advanced or Aggressive Intermediate Prostate Cancer, Randomized to Lifelong Endocrine Treatment Alone or Combined with Radiotherapy: Final Results of The Scandinavian. Eur Urol 2016;70:684-91. doi:10.1016/j.eururo.2016.03.021.

[5] Mason MD, Parulekar WR, Sydes MR, Brundage M, Kirkbride P, Gospodarowicz M, et al. Final Report of the Intergroup Randomized Study of Combined Androgen-Deprivation Therapy Plus Radiotherapy Versus Androgen-Deprivation Therapy Alone in Locally Advanced Prostate Cancer. J Clin Oncol 2015;33:2143-50. doi:10.1200/jco.2014.57.7510.

[6] Mottet N, Peneau M, Mazeron J, Molinie V, Richaud P. Addition of radiotherapy to long-term androgen deprivation in locally advanced prostate cancer: An open randomised phase 3 trial. Eur Urol 2012;62:213-9. doi:10.1016/j.eururo.2012.03.053.

[7] Van den Broeck T, Moris L, Cumberbatch M, Fossati N, Gandaglia G, Kelly B, et al. A systematic review of oncological effectiveness and harms of primary local interventions for high-risk localized and locally advanced prostate cancer. PROSPERO Int Prospect Regist Syst Rev 2017.

[8] Moher D, Liberati A, Tetzlaff J, Altman DG. Preferred Reporting Items for Systematic Reviews and MetaAnalyses: The PRISMA Statement. Phys Ther 2009;89:873-80.

[9] Higgins J, Green S. Cochrane Handbook for Systematic Reviews of Interventions. 2008.

[10] Xie W, Regan MM, Buyse M, Halabi S, Kantoff P, Sartor O, et al. Metastasis-free survival is a strong Surrogate of overall survival in localized prostate cancer. J Clin Oncol 2017;35:3097-104. doi:10.1200/JCO.2017.73.9987.

[11] Arcangeli G, Saracino B AS et al. Moderate Hypofractionation in High-Risk, Organ-Confined Prostate Cancer: Final Results of a Phase III Randomized Trial. J Clin Oncol 2017;35:1891-7. doi:10.1016/j.juro.2017.11.107.

[12] Arcangeli S, Strigari L, Gomellini S, Saracino B, Petrongari MG, Pinnarò P, et al. Updated results and patterns of failure in a randomized hypofractionation trial for high-risk prostate cancer. Int J Radiat Oncol Biol Phys 2012;84:1172-8. doi:10.1016/j.ijrobp.2012.02.049.

[13] Denham JW, Joseph D, Lamb DS, Spry NA, Duchesne G, Matthews J, et al. Short-term androgen suppression and radiotherapy versus intermediate-term androgen suppression and radiotherapy, with or without zoledronic acid, in men with locally advanced prostate cancer (TROG 03.04 RADAR): 10-year results from a randomised, phase 3, . Lancet Oncol 2019;20:267-81. doi:10.1016/S14702045(18)30757-5.

[14] Denham JW, Steigler A, Lamb DS, Joseph D, Turner S, Matthews J, et al. Short-term neoadjuvant androgen deprivation and radiotherapy for locally advanced prostate cancer: 10-year data from the TROG 96.01 randomised trial. Lancet Oncol 2011;12:451-9. doi:10.1016/S1470-2045(11)70063-8.

[15] Dignam JJ, Hamstra DA, Lepor H, Grignon D, Brereton H, Currey A, et al. Time interval to biochemical failure as a surrogate end point in locally advanced prostate cancer: Analysis of randomized trial NRG/ RTOG 9202. J Clin Oncol 2019;37:213-21. doi:10.1200/JCO.18.00154.

[16] Iversen P, McLeod DG, See WA, Morris T, Armstrong J, Wirth MP. Antiandrogen monotherapy in patients with localized or locally advanced prostate cancer: Final results from the bicalutamide Early Prostate Cancer programme at a median follow-up of 9.7 years. BJU Int 2010;105:1074-81. doi:10.1111/j.1464-410X.2010.09319.x. 
[17] Lawton CAF, Lin X, Hanks GE, Lepor H, Grignon DJ, Brereton HD, et al. Duration of Androgen Deprivation in Locally Advanced Prostate Cancer: Long-Term Update of NRG Oncology RTOG 9202. Int J Radiat Oncol Biol Phys 2017;98:296-303. doi:10.1016/j.ijrobp.2017.02.004.

[18] Nabid A, Carrier N, Martin AG, Bahary JP, Lemaire C, Vass S, et al. Duration of Androgen Deprivation Therapy in High-risk Prostate Cancer: A Randomized Phase III Trial. Eur Urol 2018;74:432-41. doi:10.1016/j.eururo.2018.06.018.

[19] Roach M, Moughan J, Lawton CAF, Dicker AP, Zeitzer KL, Gore EM, et al. Sequence of hormonal therapy and radiotherapy field size in unfavourable, localised prostate cancer (NRG/RTOG 9413): long-term results of a randomised, phase 3 trial. Lancet Oncol 2018;19:1504-15. doi:10.1016/s14702045(18)30528-x.

[20] Rodda S, Morris WJ, Hamm J, Duncan G. ASCENDE-RT: An Analysis of Health-Related Quality of Life for a Randomized Trial Comparing Low-Dose-Rate Brachytherapy Boost With Dose-Escalated External Beam Boost for High- and Intermediate-Risk Prostate Cancer. Int J Radiat Oncol Biol Phys 2017;98:581-9. doi:10.1016/j.ijrobp.2017.02.027.

[21] Rodda S, Tyldesley S, Morris WJ, Keyes M, Halperin R, Pai H, et al. ASCENDE-RT: An Analysis of Treatment-Related Morbidity for a Randomized Trial Comparing a Low-Dose-Rate Brachytherapy Boost with a Dose-Escalated External Beam Boost for High- and Intermediate-Risk Prostate Cancer. Int J Radiat Oncol Biol Phys 2017;98:286-95. doi:10.1016/j.ijrobp.2017.01.008.

[22] Morris WJ, Tyldesley S, Rodda S, Halperin R, Pai H, McKenzie M, et al. Androgen Suppression Combined with Elective Nodal and Dose Escalated Radiation Therapy (the ASCENDE-RT Trial): An Analysis of Survival Endpoints for a Randomized Trial Comparing a Low-Dose-Rate Brachytherapy Boost to a DoseEscalated External Beam Boost f. Int J Radiat Oncol Biol Phys 2017;98:275-85.

doi:10.1016/j.ijrobp.2016.11.026.

[23] Armstrong JG, Gillham CM, Dunne MT, Fitzpatrick DA, Finn MA, Cannon ME, et al. A randomized trial (Irish Clinical Oncology Research Group 97-01) comparing short versus protracted neoadjuvant hormonal therapy before radiotherapy for localized prostate cancer. Int J Radiat Oncol Biol Phys 2011;81:35-45. doi:10.1016/j.ijrobp.2010.04.065.

[24] Rosenthal SA, Hu C, Sartor O, Gomella LG, Amin MB, Purdy J, et al. Effect of Chemotherapy With Docetaxel With Androgen Suppression and Radiotherapy for Localized High-Risk Prostate Cancer: The Randomized Phase III NRG Oncology RTOG 0521 Trial. J Clin Oncol 2019:JCO.18.02158. doi:10.1200/JCO.18.02158.

[25] Rosenthal S, Hunt D, Sartor A PK et al. A Phase III trial of 2 Years of Androgen Suppression (AS) and Radiation Therapy (RT) with or without Adjuvant Chemotherapy (CT) for High-Risk Prostate Cancer: Final Results of Radiation Therapy Oncology Group (RTOG) Phase III Randomized Trial NRG Oncology. INt J Radiat Oncol Biol Phys 2015;93:294-302. doi:10.1016/j.ijrobp.2015.05.024.A.

[26] See WA, Tyrrell CJ. The addition of bicalutamide $150 \mathrm{mg}$ to radiotherapy significantly improves overall survival in men with locally advanced prostate cancer. J Cancer Res Clin Oncol 2006;132. doi:10.1007/s00432-006-0132-6.

[27] Zapatero A, Guerrero A, Maldonado X et al. High-dose radiotherapy with short-term or long-term androgen deprivation in localised prostate cancer (DART01/05 GICOR): A randomised, controlled, phase 3 trial. Lancet Oncol 2015;16:320-7. doi:10.1016/j.juro.2015.07.009.

[28] Blanchard P, Faivre L, Lesaunier F, Salem N, Mesgouez-Nebout N, Deniau-Alexandre E, et al. Outcome according to elective pelvic radiation therapy in patients with high-risk localized prostate cancer: $\mathrm{A}$ secondary analysis of the GETUG 12 phase 3 randomized trial. Int J Radiat Oncol Biol Phys 2016;94:8592. doi:10.1016/j.ijrobp.2015.09.020.

[29] Bolla M, de Reijke TM, Van Tienhoven G, Van den Bergh ACM, Oddens J, Poortmans PMP, et al. Duration of androgen suppression in the treatment of prostate cancer. N Engl J Med 2009;360:251627. doi:10.1056/NEJMoa0810095.

[30] Bolla M, Collette L, Blank L, Warde P, Dubois JB, Mirimanoff RO, et al. Long-term results with immediate androgen suppression and external irradiation in patients with locally advanced prostate cancer (an EORTC study): A phase III randomised trial. Lancet 2002;360:103-8. doi:10.1016/S0140-6736(02)094084.

[31] Bolla M, Van Poppel H, Tombal B, Vekemans K, Da Pozzo L, De Reijke TM, et al. Postoperative radiotherapy after radical prostatectomy for high-risk prostate cancer: Long-term results of a randomised controlled trial (EORTC trial 22911). Lancet 2012;380:2018-27. doi:10.1016/S01406736(12)61253-7.

[32] Bolla M, Van Tienhoven G, Warde P, Dubois JB, Mirimanoff RO, Storme G, et al. External irradiation 
with or without long-term androgen suppression for prostate cancer with high metastatic risk: 10-year results of an EORTC randomised study. Lancet Oncol 2010;11:1066-73. doi:10.1016/S14702045(10)70223-0.

[33] Carles J, Gallardo E, Doménech M, Font A, Bellmunt J, Figols M, et al. Phase 2 Randomized Study of Radiation Therapy and 3-Year Androgen Deprivation With or Without Concurrent Weekly Docetaxel in High-Risk Localized Prostate Cancer Patients. Int J Radiat Oncol Biol Phys 2019;103:344-52.

doi:10.1016/j.ijrobp.2018.10.005.

[34] Dearnaley DP, Jovic G, Syndikus I, Khoo V, Cowan RA, Graham JD, et al. Escalated-dose versus controldose conformal radiotherapy for prostate cancer: Long-term results from the MRC RT01 randomised controlled trial. Lancet Oncol 2014;15:464-73. doi:10.1016/S1470-2045(14)70040-3.

[35] Boorjian SA, Karnes RJ, Viterbo R, Rangel LJ, Bergstralh EJ, Horwitz EM, et al. Long-term survival after radical prostatectomy versus external-beam radiotherapy for patients with high-risk prostate cancer. Cancer 2011;117:2883-91. doi:10.1002/cncr.25900.

[36] Miller ET, Chamie K, Kwan L, Lewis MS, Knudsen BS, Garraway IP. Impact of treatment on progression to castration-resistance, metastases, and death in men with localized high-grade prostate cancer. Cancer Med 2017;6:163-72. doi:10.1002/cam4.981.

[37] Tai P, Tonita J, Woitas C, Zhu T, Joseph K, Skarsgard D. Treatment outcomes in non-metastatic prostate cancer patients with ultra-high prostate-specific antigen. Int J Radiat Oncol Biol Phys 2012;83:e525-30. doi:10.1016/j.ijrobp.2012.01.041.

[38] Sheng W, Kirschner-Hermanns R, Zhang H. Elderly patients aged $\geq 75$ years with locally advanced prostate cancer may benefit from local treatment: a population-based propensity score-adjusted analysis. World J Urol 2018:1-9. doi:10.1007/s00345-018-2389-1.

[39] Abdollah F, Schmitges J, Sun M, Jeldres C, Tian Z, Briganti A, et al. Comparison of mortality outcomes after radical prostatectomy versus radiotherapy in patients with localized prostate cancer: $A$ population-based analysis. Int J Urol 2012;19:836-44. doi:10.1111/j.1442-2042.2012.03052.x.

[40] Tilki D, Chen M-H, Wu J, Huland H, Graefen M, Braccioforte M, et al. Surgery vs Radiotherapy in the Management of Biopsy Gleason Score 9-10 Prostate Cancer and the Risk of Mortality. JAMA Oncol 2018:1-9. doi:10.1001/jamaoncol.2018.4836.

[41] Stokes SH. Comparison of biochemical disease-free survival of patients with localized carcinoma of the prostate undergoing radical prostatectomy, transperineal ultrasound-guided radioactive seed implantation, or definitive external beam irradiation. Int J Radiat Oncol Biol Phys 2000;47:129-36. doi:10.1016/S0360-3016(99)00526-X.

[42] Berg S, Cole AP, Krimphove MJ, Nabi J, Marchese M, Lipsitz SR, et al. Comparative Effectiveness of Radical Prostatectomy Versus External Beam Radiation Therapy Plus Brachytherapy in Patients with High-risk Localized Prostate Cancer. Eur Urol 2018:2-5. doi:10.1016/j.eururo.2018.10.032.

[43] Bandini M, Marchioni M, Preisser F, Zaffuto E, Tian Z, Tilki D, et al. Survival after radical prostatectomy or radiotherapy for locally advanced (cT3) prostate cancer. World J Urol 2018;36:1399-407. doi:10.1007/s00345-018-2310-y.

[44] Abdollah F, Sun M, Thuret R, Jeldres C, Tian Z, Briganti A, et al. A competing-risks analysis of survival after alternative treatment modalities for prostate cancer patients: 1988-2006. Eur Urol 2011;59:8895. doi:10.1016/j.eururo.2010.10.003.

[45] Robinson D, Garmo H, Lissbrant IF, Widmark A, Pettersson A, Gunnlaugsson A, et al. Prostate Cancer Death After Radiotherapy or Radical Prostatectomy: A Nationwide Population-based Observational Study. Eur Urol 2018;73:502-11. doi:10.1016/j.eururo.2017.11.039.

[46] Reichard CA, Hoffman KE, Tang C, Williams SB, Allen PK, Achim MF, et al. Radical prostatectomy or radiotherapy for high- and very high-risk prostate cancer: a multidisciplinary prostate cancer clinic experience of patients eligible for either treatment. BJU Int 2019. doi:10.1111/bju.14780.

[47] Ciezki JP, Weller M, Reddy CA, Kittel J, Singh H, Tendulkar R, et al. A Comparison Between Low-DoseRate Brachytherapy With or Without Androgen Deprivation, External Beam Radiation Therapy With or Without Androgen Deprivation, and Radical Prostatectomy With or Without Adjuvant or Salvage Radiation Therapy for High-Risk Pros. Int J Radiat Oncol Biol Phys 2017;97:962-75. doi:10.1016/j.ijrobp.2016.12.014.

[48] Merino T, San Francisco IF, Rojas PA, Bettoli P, Zúñiga Á, Besa P. Intensity-modulated radiotherapy versus radical prostatectomy in patients with localized prostate cancer: Long-term follow-up. BMC Cancer 2013;13. doi:10.1186/1471-2407-13-530.

[49] Sussman R, Carvalho FLF, Harbin A, Zheng C, Lynch JH, Stamatakis L, et al. Survival and secondary interventions following treatment for locally-advanced prostate cancer 2018:9516-24. 
[50] Fletcher SG, Mills SE, Smolkin ME, Theodorescu D. Case-Matched comparison of contemporary radiation therapy to surgery in patients with locally advanced prostate cancer. Int J Radiat Oncol Biol Phys 2006;66:1092-9. doi:10.1016/j.ijrobp.2006.06.019.

[51] Lee JY, Cho KS, Kwon JK, Jeh SU, Kang HW, Diaz RR, et al. A Competing Risk Analysis of Cancer-Specific Mortality of Initial Treatment with Radical Prostatectomy versus Radiation Therapy in Clinically Localized High-Risk Prostate Cancer. Ann Surg Oncol 2014;21:4026-33. doi:10.1245/s10434-014-37809.

[52] Greenberg DC, Lophatananon A, Wright KA, Muir KR, Gnanapragasam VJ. Trends and outcome from radical therapy for primary non-metastatic prostate cancer in $\alpha$ UK population. PLoS One 2015;10:1-12. doi:10.1371/journal.pone.0119494.

[53] Tyson MD, Koyama T, Lee D, Hoffman KE, Resnick MJ, Wu X-C, et al. Effect of Prostate Cancer Severity on Functional Outcomes After Localized Treatment: Comparative Effectiveness Analysis of Surgery and Radiation Study Results. Eur Urol 2018;74:26-33. doi:10.1016/j.eururo.2018.02.012.

[54] Caño-Velasco J, Herranz-Amo F, Barbas-Bernardos G, Polanco-Pujol L, Verdú-Tartajo F, Lledó-García E, et al. Oncological control in high-risk prostate cancer after radical prostatectomy and salvage radiotherapy compared to radiotherapy plus primary hormone therapy. Actas Urol Esp 2019;43:190-7. doi:10.1016/j.acuro.2018.07.007.

[55] Yamamoto S, Kawakami S, Yonese J, Fujii Y, Urakami S, Kitsukawa S, et al. Long-term oncological outcome in men with T3 prostate cancer: radical prostatectomy versus external-beam radiation therapy at a single institution. Int J Clin Oncol 2014;19:1085-91. doi:10.1007/s10147-013-0654-2.

[56] Jang TL, Patel N, Faiena I, Radadia KD, Moore DF, Lsamra SE, et al. Comparative effectiveness of radical prostatectomy with adjuvant radiotherapy versus radiotherapy plus androgen deprivation therapy for men with advanced prostate cancer. Cancer 2018;124:4010-22. doi:10.1002/cncr.31726.

[57] Seisen T, Vetterlein MW, Karabon P, Jindal T, Sood A, Nocera L, et al. Efficacy of Local Treatment in Prostate Cancer Patients with Clinically Pelvic Lymph Node-positive Disease at Initial Diagnosis. Eur Urol 2017;73:452-61. doi:10.1016/j.eururo.2017.08.011.

[58] Fosså SD, Nilssen Y, Kvåle R, Hernes E, Axcrona K, Møller B. Treatment and 5-year survival in patients with nonmetastatic prostate cancer: The Norwegian experience. Urology 2014;83:146-52. doi:10.1016/j.urology.2013.08.081.

[59] Gu X, Gao X, Cui M, Xie M, Ma M, Qin S, et al. Survival outcomes of radical prostatectomy and external beam radiotherapy in clinically localized high-risk prostate cancer: A population-based, propensity score matched study. Cancer Manag Res 2018;10:1061-7. doi:10.2147/CMAR.S157442.

[60] Koo KC, Cho JS, Bang WJ, Lee SH, Cho SY, Kim S II, et al. Cancer-Specific Mortality Among Korean Men with Localized or Locally Advanced Prostate Cancer Treated with Radical Prostatectomy Versus Radiotherapy: A Multi-Center Study Using Propensity Scoring and Competing Risk Regression Analyses. Cancer Res Treat 2017:1-9. doi:10.4143/crt.2017.004.

[61] Sooriakumaran P, Nyberg T, Akre O, Haendler L, Heus I, Olsson M, et al. Comparative effectiveness of radical prostatectomy and radiotherapy in prostate cancer: observational study of mortality outcomes. Bmj 2014;348:g1502-g1502. doi:10.1136/bmj.g1502.

[62] Feldman AS, Meyer CP, Sanchez A, Krasnova A, Reznor G, Menon M, et al. Morbidity and Mortality of Locally Advanced Prostate Cancer: A Population Based Analysis Comparing Radical Prostatectomy versus External Beam Radiation. J Urol 2017;198:1061-8. doi:10.1016/j.juro.2017.05.073.

[63] Caño-Velasco J, Herranz-Amo F, Barbas-Bernardos G, Polanco-Pujol L, Hernández-Cavieres J, LledóGarcía E, et al. Differences in overall survival and cancer-specific survival in high-risk prostate cancer patients according to the primary treatment. Actas Urol Esp 2019;43:91-8.

doi:10.1016/j.acuro.2018.06.006.

[64] Gunnarsson O, Schelin S, Brudin L, Carlsson S, Damber JE. Triple treatment of high-risk prostate cancer. A matched cohort study with up to 19 years follow-up comparing survival outcomes after triple treatment and treatment with hormones and radiotherapy. Scand J Urol 2019;53:102-8. doi:10.1080/21681805.2019.1600580.

[65] Zeliadt SB, Potosky AL, Penson DF, Etzioni R. Survival benefit associated with adjuvant androgen deprivation therapy combined with radiotherapy for high- and low-risk patients with nonmetastatic prostate cancer. Int J Radiat Oncol Biol Phys 2006;66:395-402. doi:10.1016/j.ijrobp.2006.04.048.

[66] Krauss D, Kestin L, Ye H, Brabbins D, Ghilezan M, Gustafson G, et al. Lack of benefit for the addition of androgen deprivation therapy to dose-escalated radiotherapy in the treatment of intermediate- and high-risk prostate cancer. Int J Radiat Oncol Biol Phys 2011;80:1064-71. doi:10.1016/j.ijrobp.2010.04.004. 
[67] Horwitz EM, Winter K, Hanks GE, Lawton CA, Russell AH, Machtay M. Subset analysis of RTOG 85-31 and 86-10 indicates an advantage for long-term vs. short-term adjuvant hormones for patients with locally advanced nonmetastatic prostate cancer treated with radiation therapy. Int J Radiat Oncol Biol Phys 2001;49:947-56. doi:10.1016/S0360-3016(00)01443-7.

[68] Feng FY, Blas K, Olson K, Stenmark M, Sandler H, Hamstra DA. Retrospective evaluation reveals that long-term androgen deprivation therapy improves cause-specific and overall survival in the setting of dose-escalated radiation for high-risk prostate cancer. Int J Radiat Oncol Biol Phys 2013;86:64-71. doi:10.1016/j.ijrobp.2012.11.024.

[69] D'Amico A V., Denham JW, Bolla M, Collette L, Lamb DS, Tai KH, et al. Short- vs long-term androgen suppression plus external beam radiation therapy and survival in men of advanced age with nodenegative high-risk adenocarcinoma of the prostate. Cancer 2007;109:2004-10. doi:10.1002/cncr.22628.

[70] Zwahlen DR, Andrianopoulos N, Matheson B, Duchesne GM, Millar JL. High-dose-rate brachytherapy in combination with conformal external beam radiotherapy in the treatment of prostate cancer. Brachytherapy 2010;9:27-35. doi:10.1016/j.brachy.2009.04.007.

[71] Yamazaki H, Masui K, Suzuki G, Nakamura S, Shimizu D, Nishikawa T, et al. High-dose-rate brachytherapy monotherapy versus image-guided intensity-modulated radiotherapy with helical tomotherapy for patients with localized prostate cancer. Cancers (Basel) 2018;10:1-12. doi:10.3390/cancers10090322.

[72] Wedde TB, Lilleby W, Russnes KM, Tafjord G, Fosså SD, Småstuen MC, et al. Ten-year survival after High-Dose-Rate Brachytherapy combined with External Beam Radiation Therapy in high-risk prostate cancer: A comparison with the Norwegian SPCG-7 cohort. Radiother Oncol 2018:5-11. doi:10.1016/j.radonc.2018.10.013.

[73] Umezawa R, Inaba K, Nakamura S, Wakita A, Okamoto H, Tsuchida K, et al. Dose escalation of external beam radiotherapy for high-risk prostate cancer-Impact of multiple high-risk factor. Asian J Urol 2017:1-8. doi:10.1016/j.ajur.2017.07.002.

[74] Tsubokura T, Yamazaki H, Masui K, Sasaki N, Shimizu D, Suzuki G, et al. Comparison of image-guided intensity-modulated radiotherapy and low-dose rate brachytherapy with or without external beam radiotherapy in patients with localized prostate Cancer. Sci Rep 2018;8:2-7. doi:10.1038/s41598-01828730-1.

[75] Tomita N, Soga N, Ogura Y, Furusawa J, Shimizu H, Adachi S, et al. Effects of Dose-Escalated Radiotherapy in Combination With Long-Term Androgen Deprivation on Prostate Cancer. Br J Radiol 2018;91. doi:10.1259/bjr.20170431.

[76] Shilkrut M, Merrick GS, McLaughlin PW, Stenmark MH, Abu-Isa E, Vance SM, et al. The addition of lowdose-rate brachytherapy and androgen-deprivation therapy decreases biochemical failure and prostate cancer death compared with dose-escalated external-beam radiation therapy for high-risk prostate cancer. Cancer 2013;119:681-90. doi:10.1002/cncr.27784.

[77] Shen X, Keith SW, Mishra M V., Dicker AP, Showalter TN. The impact of brachytherapy on prostate cancer-specific mortality for definitive radiation therapy of high-grade prostate cancer: A populationbased analysis. Int J Radiat Oncol Biol Phys 2012;83:1154-9. doi:10.1016/j.ijrobp.2011.09.055.

[78] Sandler KA, Cook RR, Ciezki JP, Ross AE, Pomerantz MM, Nguyen PL, et al. Prostate-only Versus Wholepelvis Radiation with or Without a Brachytherapy Boost for Gleason Grade Group 5 Prostate Cancer: A Retrospective Analysis. Eur Urol 2019:1-8. doi:10.1016/j.eururo.2019.03.022.

[79] Ricco A, Hanlon A, Lanciano R. Propensity Score Matched Comparison of Intensity Modulated Radiation Therapy vs Stereotactic Body Radiation Therapy for Localized Prostate Cancer: A Survival Analysis from the National Cancer Database. Front Oncol 2017;7:1-10. doi:10.3389/fonc.2017.00185.

[80] Pahlajani N, Ruth KJ, Buyyounouski MK, Chen DYT, Horwitz EM, Hanks GE, et al. Radiotherapy doses of $80 \mathrm{~Gy}$ and higher are associated with lower mortality in men with gleason score 8 to 10 prostate cancer. Int J Radiat Oncol Biol Phys 2012;82:1949-56. doi:10.1016/j.ijrobp.2011.04.005.

[81] Nguyen Q-N, Levy LB, Lee AK, Choi SS, Frank SJ, Pugh TJ, et al. Long-term outcomes for men with highrisk prostate cancer treated definitively with external beam radiotherapy with or without androgen deprivation. Cancer 2013;119:3265-71. doi:10.1002/cncr.28213.

[82] Luo Y, Li M, Qi H, Zhao J, Han Y, Lin Y, et al. Long-term oncologic outcomes of radiotherapy combined with maximal androgen blockade for localized, high-risk prostate cancer. World J Surg Oncol 2018;16:1-10. doi:10.1186/s12957-018-1395-5.

[83] Liss AL, Abu-Isa El, Jawad MS, Feng FY, Vance SM, Winfield RJ, et al. Combination therapy improves prostate cancer survival for patients with potentially lethal prostate cancer: The impact of Gleason pattern 5. Brachytherapy 2015;14:502-10. doi:10.1016/j.brachy.2015.02.389. 
[84] Laing R, Uribe-Lewis S, Money-Kyrle J, Perna C, Chintzoglou S, Khaksar S, et al. Low-dose-rate brachytherapy for the treatment of localised prostate cancer in men with a high risk of disease relapse. BJU Int 2018;122:610-7. doi:10.1111/bju.14223.

[85] Khor R, Duchesne G, Tai KH, Foroudi F, Chander S, Van Dyk S, et al. Direct 2-arm comparison shows benefit of high-dose-rate brachytherapy boost vs external beam radiation therapy alone for prostate cancer. Int J Radiat Oncol Biol Phys 2013;85:679-85. doi:10.1016/j.ijrobp.2012.07.006.

[86] Kent AR, Matheson B, Millar JL. Improved survival for patients with prostate cancer receiving high-doserate brachytherapy boost to EBRT compared with EBRT alone. Brachytherapy 2019;18:313-21. doi:10.1016/j.brachy.2019.01.013.

[87] Jackson MW, Amini A, Jones BL, Kavanagh B, Maroni P, Frank SJ, et al. Prostate brachytherapy, either alone or in combination with external beam radiation, is associated with longer overall survival in men with favorable pathologic Group 4 (Gleason score 8) prostate cancer. Brachytherapy 2017;16:790-6. doi:10.1016/j.brachy.2017.03.007.

[88] Incrocci L, Wortel RC, Alemayehu WG, Aluwini S, Schimmel E, Krol S, et al. Hypofractionated versus conventionally fractionated radiotherapy for patients with localised prostate cancer (HYPRO): final efficacy results from a randomised, multicentre, open-label, phase 3 trial. Lancet Oncol 2016;17:10619. doi:10.1016/S1470-2045(16)30070-5.

[89] Hall MD, Schultheiss TE, Smith DD, Tseng BP, Wong JYC. The impact of increasing dose on overall survival in prostate cancer. Radiat Oncol 2015;10:1-8. doi:10.1186/s13014-015-0419-3.

[90] Dolezel M, Odrazka K, Zouhar M, Vaculikova M, Sefrova J, Jansa J, et al. Comparing morbidity and cancer control after 3D-conformal (70/74 Gy) and intensity modulated radiotherapy (78/82 Gy) for prostate. Strahlenther Onkol 2015;191:338-46. doi:10.1007/s00066-014-0806-y.

[91] Bittner N, Merrick GS, Wallner KE, Butler WM, Galbreath R, Adamovich E. Whole-Pelvis Radiotherapy in Combination With Interstitial Brachytherapy: Does Coverage of the Pelvic Lymph Nodes Improve Treatment Outcome in High-Risk Prostate Cancer? Int J Radiat Oncol Biol Phys 2010;76:1078-84. doi:10.1016/j.jirobp.2009.02.069.

[92] Amini A, Jones B, Jackson MW, Yeh N, Waxweiler T V., Maroni P, et al. Survival outcomes of doseescalated external beam radiotherapy versus combined brachytherapy for intermediate and high risk prostate cancer using the national cancer data base. J Urol 2016;195:1453-8. doi:10.1016/j.juro.2015.11.005.

[93] Ferris MJ, Liu Y, Ao J, Zhong J, Abugideiri M, Gillespie TW, et al. The addition of chemotherapy in the definitive management of high risk prostate cancer. Urol Oncol Semin Orig Investig 2018;36:475-87. doi:10.1016/j.urolonc.2018.07.020.

[94] Fujita N, Koie T, Ohyama C, Tanaka Y, Soma O, Matsumoto T, et al. Overall survival of high-risk prostate cancer patients who received neoadjuvant chemohormonal therapy followed by radical prostatectomy at a single institution. Int J Clin Oncol 2017;22:1087-93. doi:10.1007/s10147-017-1160-8.

[95] Furubayashi N, Negishi T, Iwai H, Nagase K, Taguchi K, Shimokawa M, et al. Determination of adequate pelvic lymph node dissection range for Japanese males undergoing radical prostatectomy. Mol Clin Oncol 2017;6:775-81. doi:10.3892/mco.2017.1204.

[96] Linder BJ, Boorjian SA, Umbreit EC, Carlson RE, Rangel LJ, Bergstralh EJ, et al. Interaction of adjuvant androgen deprivation therapy with patient comorbidity status on overall survival after radical prostatectomy for high-risk prostate cancer. Int J Urol 2013;20:798-805. doi:10.1111/iju.12047.

[97] Sheng W, Zhang H, Lu Y. Survival outcomes of locally advanced prostate cancer in patients aged < 50 years after local therapy in the contemporary US population. Int Urol Nephrol 2018;50:1435-44. doi:10.1007/s11255-018-1931-9.

[98] Sooriakumaran P, Pini G, Nyberg T, Derogar M, Carlsson S, Stranne J, et al. Erectile Function and Oncologic Outcomes Following Open Retropubic and Robot-assisted Radical Prostatectomy: Results from the LAParoscopic Prostatectomy Robot Open Trial. Eur Urol 2018;73:618-27. doi:10.1016/j.eururo.2017.08.015.

[99] Hamdy F, Donovan J, Lane J, Mason M, Metcalfe C, Holding P, et al. 10-Year Outcomes After Monitoring, Surgery or Radiotherapy for Localized Prostate Cancer. N Engl J Med 2016;375:1415-24. doi:10.1016/j.eururo.2017.05.045.

[100] D’Amico A V., Moran BJ, Braccioforte MH, Dosoretz D, Salenius S, Katin M, et al. Risk of death from prostate cancer after brachytherapy alone or with radiation, androgen suppression therapy, or both in men with high-risk disease. J Clin Oncol 2009;27:3923-8. doi:10.1200/JCO.2008.20.3992.

[101] Kalbasi A, Li J, Berman AT, Swisher-McClure S, Smaldone M, Uzzo RG, et al. Dose-escalated irradiation and overall survival in men with nonmetastatic prostate cancer. JAMA Oncol 2015;1:897-906. 
doi:10.1001/jamaoncol.2015.2316.

[102] Cooperberg MR, Cowan J, Broering JM, Carroll PR. High-Risk Prostate Cancer in the United States, 19902007. World J Urol 2008;26:211-8. doi:10.1007/s00345-008-0250-7. High-Risk.

[103] Stewart SB, Boorjian SA. Radical prostatectomy in high-risk and locally advanced prostate cancer: Mayo Clinic perspective. Urol Oncol Semin Orig Investig 2015;33:235-44. doi:10.1016/j.urolonc.2014.10.003.

[104] Van Poppel H. Locally advanced and high risk prostate cancer: The best indication for initial radical prostatectomy? Asian J Urol 2014;1:40-5. doi:10.1016/j.ajur.2014.09.009.

[105] Bach C, Pisipati S, Daneshwar D, Wright M, Rowe E, Gillatt D, et al. The status of surgery in the management of high-risk prostate cancer. Nat Rev Urol 2014;11:342-51. doi:10.1038/nrurol.2014.100.

[106] Bastian PJ, Boorjian SA, Bossi A, Briganti A, Heidenreich A, Freedland SJ, et al. High-risk prostate cancer: From definition to contemporary management. Eur Urol 2012;61:1096-106. doi:10.1016/j.eururo.2012.02.031.

[107] Stranne J, Brasso K, Brennhovd B, Johansson E, Jäderling F, Kouri M, et al. SPCG-15: a prospective randomized study comparing primary radical prostatectomy and primary radiotherapy plus androgen deprivation therapy for locally advanced prostate cancer. Scand J Urol 2018;52:313-20. doi:10.1080/21681805.2018.1520295.

[108] Pearlstein KA, Basak R, Chen RC. Comparative Effectiveness of Prostate Cancer Treatment Options: Limitations of Retrospective Analysis of Cancer Registry Data. Int J Radiat Oncol Biol Phys 2019;103:1053-7. doi:10.1016/j.ijrobp.2018.08.001.

[109] Van den Broeck T, van den Bergh RCN, Arfi N, Gross T, Moris L, Briers E, et al. Prognostic Value of Biochemical Recurrence Following Treatment with Curative Intent for Prostate Cancer: A Systematic Review. Eur Urol 2018. doi:10.1016/j.eururo.2018.10.011.

[110] Fizazi K, Faivre L, Lesaunier F, Delva R, Gravis G, Rolland F, et al. Androgen deprivation therapy plus docetaxel and estramustine versus androgen deprivation therapy alone for high-risk localised prostate cancer (GETUG 12): A phase 3 randomised controlled trial. Lancet Oncol 2015;16:787-94. doi:10.1016/S1470-2045(15)00011-X.

[111] James N, Ingleby F, Clarke N, Amos C, Attard G, Cross W, et al. Docetaxel for hormone-nai"ve prostate cancer (PCa): Results from long-term follow-up of non-metastatic (MO) patients in the STAMPEDE randomised trial. Ann Oncol 2019;30. doi:10.1001/jama.1993.03500010119052.

[112] Tosco L, Briganti A, D'amico AV, Eastham J, Eisenberger M, Gleave M, et al. Systematic Review of Systemic Therapies and Therapeutic Combinations with Local Treatments for High-risk Localized Prostate Cancer. Eur Urol 2019;75:44-60. doi:10.1016/j.eururo.2018.07.027.

[113] Tilki D, Preisser F, Graefen M, Huland H, Pompe RS. External Validation of the European Association of Urology Biochemical Recurrence Risk Groups to Predict Metastasis and Mortality After Radical Prostatectomy in a European Cohort. Eur Urol 2019:1-5. doi:10.1016/j.eururo.2019.03.016.

[114] Den RB, Yousefi K, Trabulsi EJ, Abdollah F, Choeurng V, Feng FY, et al. Genomic classifier identifies men with adverse pathology after radical prostatectomy who benefit from adjuvant radiation therapy. J Clin Oncol 2015;33:944-51. doi:10.1200/JCO.2014.59.0026.

[115] Gaudreau P-O, Stagg J, Soulières D, Saad F. The Present and Future of Biomarkers in Prostate Cancer: Proteomics, Genomics, and Immunology Advancements. Biomark Cancer 2016;8s2:BIC.S31802. doi:10.4137/bic.s31802.

[116] Karnes RJ, Bergstralh EJ, Davicioni E, Ghadessi M, Buerki C, Mitra AP, et al. Validation of a Genomic Classifier that Predicts Metastasis Following Radical Prostatectomy in an At Risk Patient Population. J Urol 2013;190:2047-53. doi:10.1016/j.juro.2013.06.017.

[117] Van den Broeck T, Moris L, Gevaert T, Tosco L, Smeets E, Fishbane N, et al. Validation of the Decipher Test for Predicting Distant Metastatic Recurrence in Men with High-risk Nonmetastatic Prostate Cancer 10 Years After Surgery. Eur Urol Oncol 2019. doi:10.1016/j.euo.2018.12.007.

[118] Knoll T, Omar MI, Maclennan S, Hernández V, Canfield S, Yuan Y, et al. Key Steps in Conducting Systematic Reviews for Underpinning Clinical Practice Guidelines: Methodology of the European Association of Urology. Eur Urol 2018;73:290-300. doi:10.1016/j.eururo.2017.08.016.

[119] Sweeney C, Nakabayashi M, Regan M, Xie W, Hayes J, Keating N, et al. The Development of Intermediate Clinical Endpoints in Cancer of the Prostate (ICECaP). J Natl Cancer Inst 2015;107:djv261. doi:10.1093/jnci/djv261. 
Figures

Fig. 1 - Preferred Reporting Items for Systematic Reviews and Meta-analysis flow chart.
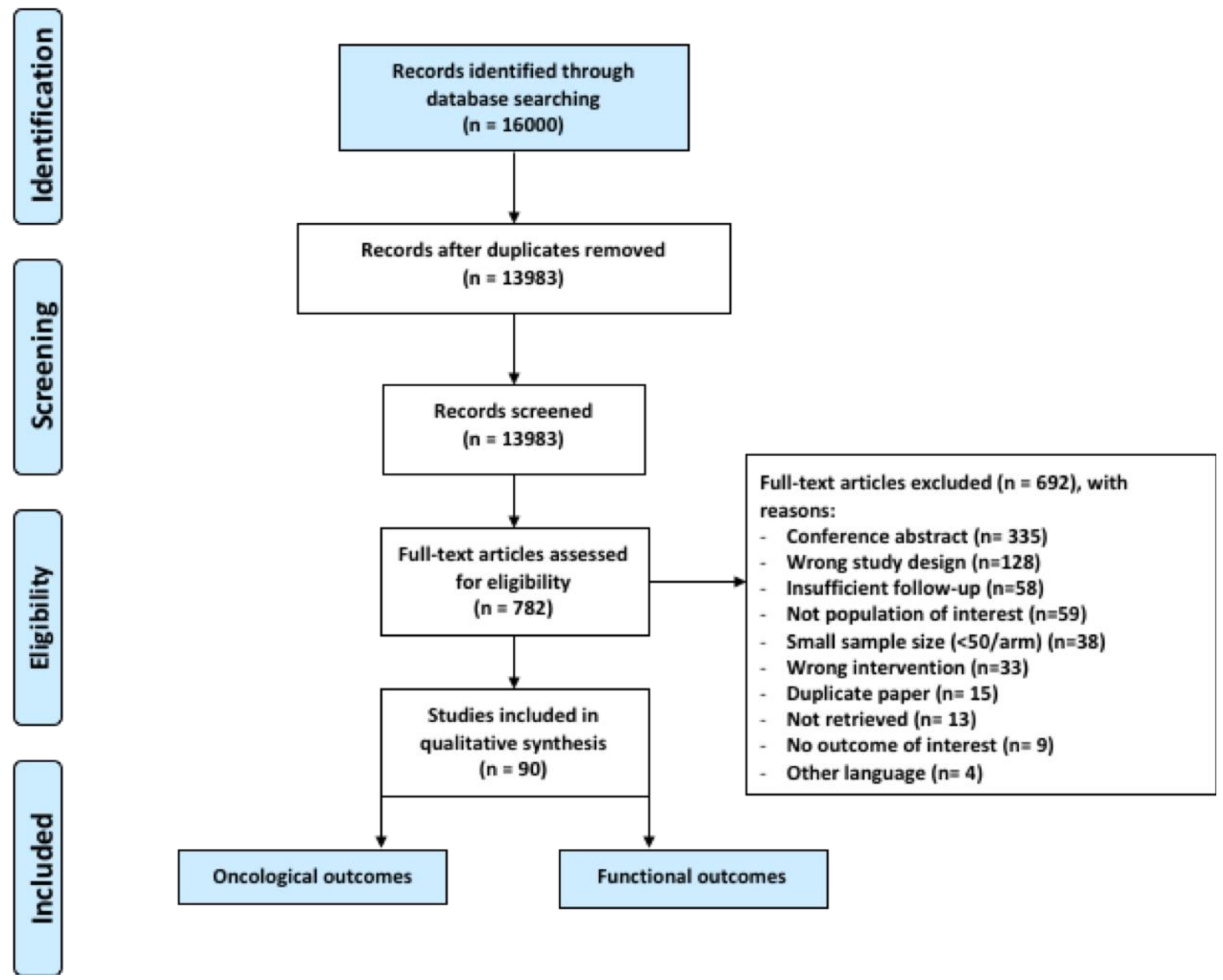
Fig. 2-Risk of bias summary graph.

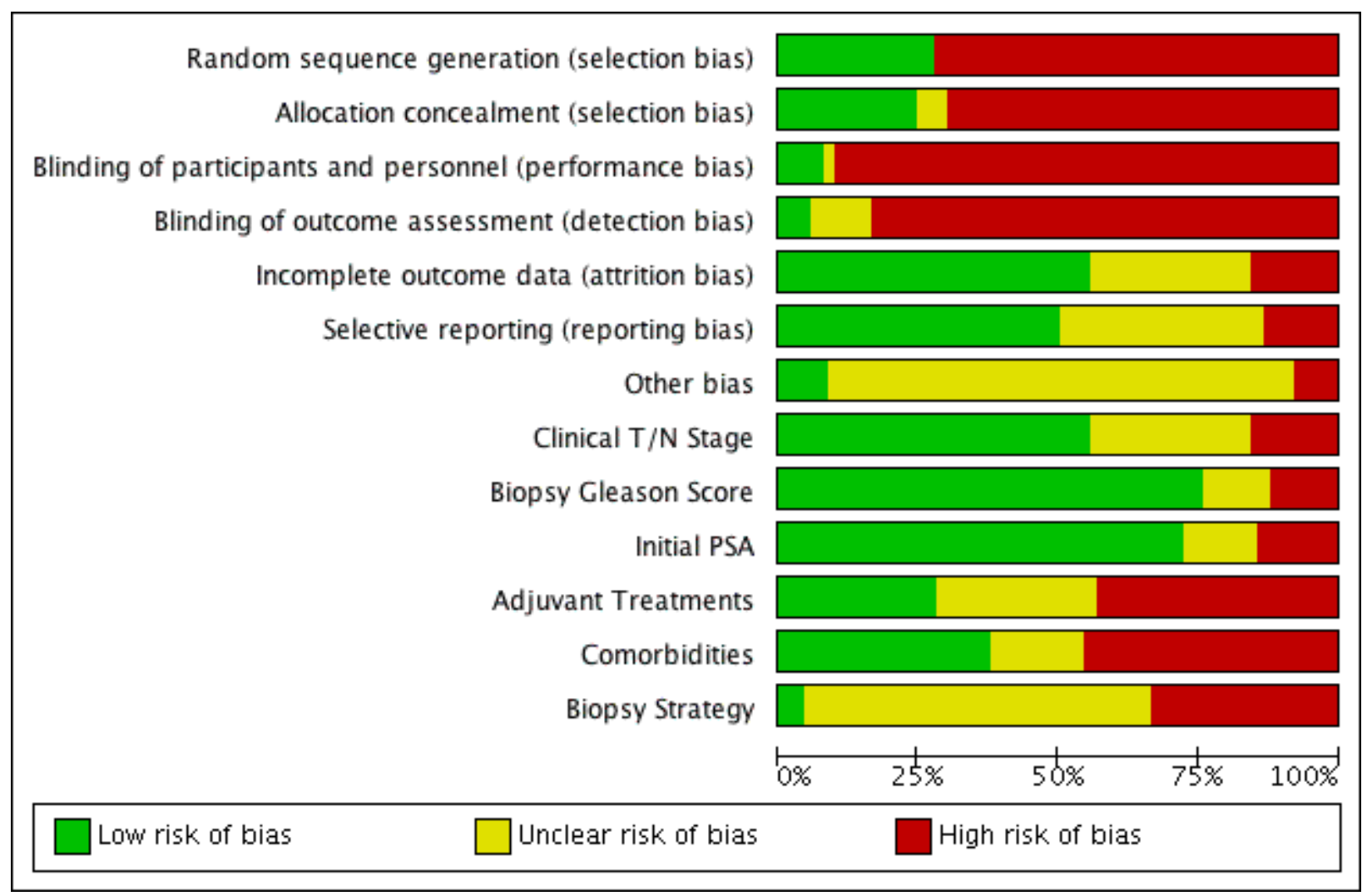

PSA = prostate-specific antigen . 
Fig.3 - Risk of bias assessment for individual studies. 


\begin{tabular}{|c|c|c|c|c|c|c|c|c|c|c|c|c|c|}
\hline & 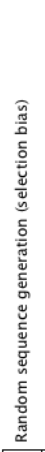 & 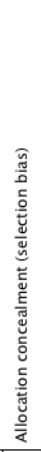 & 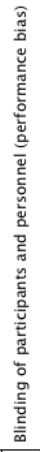 & 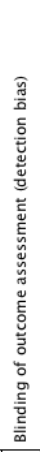 & 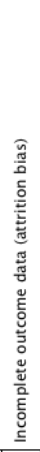 & 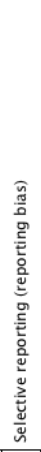 & 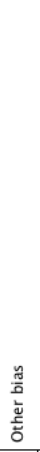 & 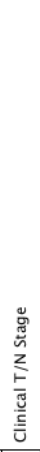 & 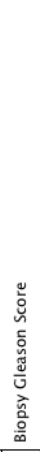 & 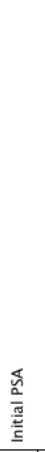 & 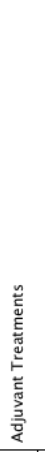 & 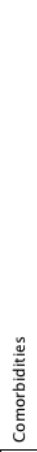 & 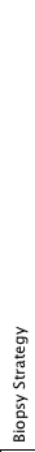 \\
\hline Abdollah 2011 (NRS) & O & ○ & $\theta$ & $\theta$ & $?$ & $?$ & $?$ & $\theta$ & $?$ & - & \begin{tabular}{|l|l|}
$?$ \\
\end{tabular} & $\theta$ & $?$ \\
\hline Abdollah 2012 (NRS, 7198) & $\theta$ & ○ & $\theta$ & $\theta$ & $\theta$ & $?$ & ๑ & $\theta$ & $?$ & $\theta$ & $?$ & $?$ & $?$ \\
\hline Amini 2016 (NRS) & O & ○ & $\theta$ & $?$ & $\theta$ & $?$ & $?$ & $?$ & $?$ & $?$ & $\theta$ & $?$ & $\theta$ \\
\hline Arcangeli 2011 (RCT) & + & 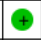 & † & $?$ & † & † & + & $\theta$ & † & $\odot$ & - & $\hookrightarrow$ & $?$ \\
\hline Arcangeli 2017 (RCT) & $\odot$ & $\hookrightarrow$ & $\theta$ & $\theta$ & † & $?$ & $?$ & † & † & $\odot$ & $?$ & $?$ & $?$ \\
\hline Armstrong 2011 (RCT) & 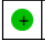 & 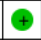 & 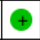 & 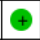 & † & 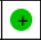 & $?$ & 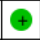 & $\hookrightarrow$ & $?$ & ○ & $\hookrightarrow$ & $?$ \\
\hline Bandini 2018 (NRS) & O & $\theta$ & $\theta$ & $\theta$ & † & † & $?$ & - & + & $\odot$ & ○ & $\Theta$ & $\theta$ \\
\hline Berg 2018 (NRS) & - & ○ & $\theta$ & ? & $\hookrightarrow$ & † & $?$ & † & † & $\odot$ & $\odot$ & $\theta$ & $\theta$ \\
\hline Bittner 2010 (NRS) & O & $\theta$ & $\theta$ & $?$ & $\theta$ & $\theta$ & $?$ & ○ & - & $\theta$ & $?$ & $?$ & $?$ \\
\hline Blanchard 2016 (NRS) & - & ? & ? & ? & ? & - & $?$ & - & † & $\odot$ & $?$ & $\hookrightarrow$ & $?$ \\
\hline Bolla 2002 (RCT) & $\odot$ & $?$ & ? & ? & ? & 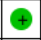 & $?$ & † & + & $\odot$ & $?$ & $\theta$ & 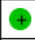 \\
\hline Bolla 2009 (RCT) & $\odot$ & $?$ & ? & $?$ & ? & $?$ & $?$ & † & † & ๑ & $?$ & † & ? \\
\hline Bolla $2010(\mathrm{RCT})$ & $\odot$ & † & $?$ & $?$ & † & † & $?$ & † & † & $?$ & $?$ & 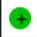 & 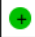 \\
\hline Bolla $2012(\mathrm{RCT})$ & $\odot$ & $\hookrightarrow$ & $\theta$ & $\theta$ & $\theta$ & 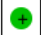 & $?$ & ๑ & ๑ & $\odot$ & 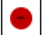 & $?$ & $?$ \\
\hline Boorjian 2011 (NRS) & $\theta$ & $?$ & $\theta$ & $?$ & $?$ & $?$ & $?$ & $?$ & ๑ & $\odot$ & $?$ & $\theta$ & - \\
\hline Cano-Velasco 2019 (NRS) & ○ & ○ & $\theta$ & $\theta$ & ๑ & $?$ & $?$ & $?$ & ๑ & $\odot$ & ○ & $\theta$ & $?$ \\
\hline Carles $2018(\mathrm{RCT})$ & $\odot$ & † & ○ & $\theta$ & † & † & $?$ & † & † & $\odot$ & $\odot$ & $\theta$ & $\theta$ \\
\hline Ciezki 2017 (NRS) & ○ & ○ & $\theta$ & O & $?$ & $?$ & $?$ & $?$ & $?$ & $?$ & ○ & $\theta$ & $?$ \\
\hline D'Amico 2007 (NRS) & ○ & ○ & 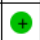 & $\theta$ & O & O & $?$ & † & ๑ & $\odot$ & $?$ & $\theta$ & $?$ \\
\hline D'Amico 2009 (NRS) & ○ & ○ & ○ & ○ & ๑ & $?$ & $?$ & $?$ & ๑ & 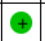 & ○ & ? & $?$ \\
\hline Dearnaley 2014 (RCT) & $\odot$ & † & $\theta$ & $\theta$ & † & ๑ & $?$ & $?$ & $?$ & $?$ & $\odot$ & $\theta$ & $?$ \\
\hline Denham 2011 (RCT) & $\odot$ & ๑ & ○ & ○ & ๑ & ๑ & $?$ & ๑ & † & $\odot$ & $?$ & $\hookrightarrow$ & $?$ \\
\hline Denham 2014 (RCT) & $\odot$ & † & $\theta$ & ? & $?$ & † & $?$ & 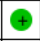 & + & ○ & ○ & $?$ & 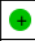 \\
\hline Denham 2019 (RCT) & $\odot$ & $\hookrightarrow$ & $\theta$ & $\theta$ & $\hookrightarrow$ & † & $?$ & 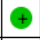 & 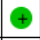 & $\odot$ & ○ & $\theta$ & $?$ \\
\hline Dignam 2019 (NRS) & - & $\theta$ & $\theta$ & ? & † & † & $?$ & † & † & $\odot$ & $?$ & † & $?$ \\
\hline Dolezel 2015 (NRS) & $\theta$ & $\theta$ & $\theta$ & $\theta$ & $\theta$ & $\theta$ & $?$ & $\theta$ & - & O & $\theta$ & $?$ & $?$ \\
\hline Feldman 2017 (NRS) & $\theta$ & $\theta$ & $\theta$ & $\theta$ & ○ & $\theta$ & $?$ & $?$ & ๑ & $\theta$ & O & $\hookrightarrow$ & $?$ \\
\hline Feng 2013 (NRS) & - & ○ & $\theta$ & $\theta$ & $?$ & $?$ & ○ & ๑) & (†) & ๑ & (†) & 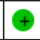 & $?$ \\
\hline Ferris 2018 (NRS) & - & ○ & $\theta$ & ○ & ๑ & $\odot$ & $?$ & † & (†) & ๑ & $?$ & ๑ & $\theta$ \\
\hline Fletcher 2006 (NRS) & $\theta$ & $\theta$ & $\theta$ & $\theta$ & $?$ & $?$ & ○ & $?$ & ๑ & 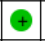 & $?$ & $?$ & $?$ \\
\hline Fossa 2014 (NRS) & O & $\theta$ & $\theta$ & $\theta$ & $?$ & $?$ & $?$ & $\theta$ & $\theta$ & O & O & ○ & $?$ \\
\hline Fujita 2017 (NRS) & $\theta$ & $\theta$ & $\theta$ & $\theta$ & $?$ & $?$ & $?$ & $?$ & ๑ & $\odot$ & O & ○ & $?$ \\
\hline Furubayashi 2017 (NRS) & $\theta$ & $\theta$ & $\theta$ & $\theta$ & $?$ & $?$ & $?$ & $?$ & $?$ & $?$ & O & ○ & $?$ \\
\hline Greenberg 2015 (NRS) & O & $\theta$ & O & $\theta$ & $?$ & $?$ & $?$ & - & - & ○ & O & ○ & $?$ \\
\hline Gu 2018 (NRS) & O & ? & ? & ? & $?$ & † & $?$ & † & † & + & 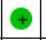 & ? & $\theta$ \\
\hline Gunnarsson 2019 (NRS) & $\theta$ & $\theta$ & ? & $\theta$ & † & $?$ & $?$ & $?$ & + & $\odot$ & ○ & $\theta$ & $\theta$ \\
\hline Hall 2015 (NRS) & O & ○ & ? & ? & $?$ & $?$ & $?$ & $?$ & $\theta$ & $\theta$ & (†) & + & $?$ \\
\hline Horwitz 2001 ((NRS) & + & † & † & 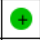 & $?$ & † & + & 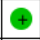 & † & + & + & 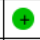 & $?$ \\
\hline Horwitz 2008 (RCT) & 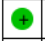 & 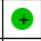 & 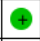 & † & $\hookrightarrow$ & † & + & + & + & $\odot$ & + & 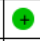 & $?$ \\
\hline Incrocci 2016 (RCT) & $\odot$ & 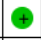 & $\theta$ & ? & 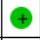 & 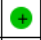 & $?$ & $?$ & + & $\odot$ & $\odot$ & $?$ & $?$ \\
\hline wersen $2010(\mathrm{RCT})$ & $\odot$ & $\hookrightarrow$ & 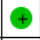 & 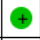 & $\hookrightarrow$ & † & $\odot$ & † & 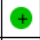 & $?$ & $\odot$ & † & $?$ \\
\hline Jackson 2017 (NRS) & - & ? & $\theta$ & O & $?$ & + & ? & + & + & $?$ & + & + & $?$ \\
\hline Jang 2018 (NRS) & ○ & ? & ○ & ? & 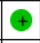 & 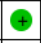 & $?$ & + & + & + & O & + & ○ \\
\hline Kalbasi 2015 (NRS) & - & ? & O & $\theta$ & $?$ & $?$ & $?$ & $?$ & + & + & O & ○ & $?$ \\
\hline Kent 2019 (NRS) & - & ? & ○ & ○ & (†) & $?$ & $?$ & $?$ & $?$ & $?$ & $?$ & $?$ & $?$ \\
\hline Khor 2013 (NRS) & ○ & ○ & O & $?$ & ○ & ○ & ? & † & † & + & $?$ & $\hookrightarrow$ & $?$ \\
\hline Koo 2017 (NRS) & ○ & ? & O & ○ & † & ○ & ○ & † & † & + & $?$ & $\hookrightarrow$ & O \\
\hline Krauss 2011 (NRS) & ○ & O & ? & ? & $?$ & $?$ & $?$ & $?$ & $?$ & O & O & $?$ & $?$ \\
\hline Laing 2018 (NRS) & ○ & O & O & ○ & † & 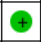 & $?$ & 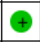 & † & $\odot$ & O & ○ & O \\
\hline Lawton 2017 (RCT) & 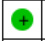 & † & $?$ & $?$ & † & † & $?$ & 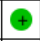 & 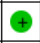 & $\odot$ & $\theta$ & $\odot$ & $?$ \\
\hline Lee 2014 (NRS) & 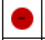 & $?$ & ? & ? & $?$ & † & $?$ & $?$ & † & $\odot$ & $?$ & + & $?$ \\
\hline
\end{tabular}


NRS = non-randomized study; RCT = randomized clinical trial. 


\section{Letter to the reviewers -Eur Urol}

We thank all reviewers for their time and effort in evaluating our work.

We would like to address these comments and highlight the changes to improve the quality of this work.

\section{Reviewer 1:}

We rewrote parts of the text as well as changed the structure and corrected for any misspellings to make it easier to read.

The scope of this project was to perform a formal systematic review with a solid methodological approach. Therefore, it summarizes all the available and relevant evidence on which the various treatment strategies rely and evaluate the quality of the included studies. We cannot exclude papers based on their quality. This can be, however, a clear sign that proper, high quality studies need to be performed in certain fields.

We do agree with the fact that outdated treatments should not be recommended. We highlighted this problem in the text and created a separate table with studies using treatment protocols (EBRT $<70 G y$ ) that should be recommended anymore. However, if we limit too much the inclusion period, the follow-up period is too short and will never lead to clinically significant findings (distant metastasis free survival, prostate cancer specific survival).

Finally, regarding the review of Tosco et al, this paper was not available and not registered in the PROSPERO database at the time our systematic review was performed. Furthermore, it highlights very distinct topics compared to our work:

- It focusses mainly on systemic treatment ( $\Leftrightarrow$ we focus on primary local therapies)

- We decided to work with pre-treatment criteria (clinical classification system) only, while Tosco et al also included papers based on post-surgery results

- In fact, we see both papers as complementary: the initial management for patients is of major importance (our focus) and the treatment will later be individualized based on posttreatment (pathological) results ( $\mathrm{pT}, \mathrm{pN}$, post-PSA, ISUP grading etc), which is more the focus of Tosco's paper.

We adapted the text so that this complementary aspect is more clear, highlighting the importance of the two papers.

\section{Reviewer 2:}

Reviewer 2 also mentions the Tosco SR in which we refer to our previous answer to reviewer 1.

Apart from two RCTs on EBRT and ADT duration, the quality of the evidence for treatment of locally advanced PCa remains low. It is clear and correct that treatment strategies that we offer should be individualized and based on the available evidence at that time. The focus of the systematic review was highlighting this existing evidence on the primary local treatment. We do not give recommendation on the total clinical pathway for each patient. Since the paper by Gillessen et al. is a consensus paper, these results are not an intended subject of a systematic review.

Due to the heterogeneity in the included studies, only a narrative review could be performed. Even though, the current evidence does not allow us to put RP forward as the first therapeutic option in this patient population. We agree with the statement on personalized medicine, but this should be based on the available evidence and discussed with each patient individually. 
Suggestion concerning the introduction were taken into account and the text was adapted accordingly. We clarified active treatment (= curative treatment).

We updated the sections evidence acquisition and evidence synthesis. Since this is already an extensive review, we decided to report exclusion criteria in the supplementary text. We reported for each category, the number of RCT and NRS (non-randomized) studies, which translates into LEs. We believe that adding LE information will impair legibility.

In regard to the comment concerning EBRT alone versus EBRT + ADT, the benefit of ADT is indeed confirmed by several RCTs. Still discussion remains about the duration of ADT. Two or three years ADT have both been shown to give a benefit, but have never been compared directly. Intermediate duration (as reported in the study by Nabid et al.) is highly questionable and the study has critically been commented on in our SR. We agree that comorbidity at the time of diagnosis must be taken into account when deciding on ADT duration but is remains unclear if this should be the only or main factor to decide between 2 and 3 years of ADT.

\section{Reviewer 3:}

The reviewer correctly pointed out that we did not reported on ablative therapies. Neither HIFU nor Cryotherapy/ablation nor Photodynamics are reasonable alternatives to the established curative treatment options for high-risk patients, according to the latest EAU guidelines. For this systematic review, we decided upfront to focus on established treatment modalities only. Papers with ablative treatment modality in one (or more) arms were therefore excluded.

We discussed the use of chemotherapy as part of multimodality therapy more in detail, with attention to the recently published studies (RTOG 0512, STAMPEDE, GETUG 12). However, our systematic review focusses mainly on local treatment modalities for high-risk and locally advanced prostate cancer.

We agree with the fact that in some of the included studies, the EBRT dose are suboptimal and should not be recommended any more in daily practice. We clarified this throughout the text and we created a separate table with studies reporting on EBRT doses below 70Gy to separate them from studies with accurate doses. By excluding these studies (4 different studies) the observation did not change. However, due to low level of evidence, we cannot conclude that one (RP or EBRT) is superior to the other. Concerning our current conclusion: we did not state that RP is better nor that they are equal. We stated that no superiority of any local modality has been shown be superior with any other, which is fair as this is only based on published data.

\section{Reviewer 4:}

We agree with the fact that in some of the included studies, the EBRT dose are suboptimal and should not be recommended any more in daily practice. Reviewer 1 also mentions this and we refer to our previous answer to reviewer 1. In short, we clarified this throughout the text and we created a separate table with studies reporting on EBRT doses below 70Gy to separate them from studies with accurate doses. By excluding these studies (4 different studies), the observation did not change. This is also explained above, in one of the replies to the first reviewer. However, due to low level of evidence, we cannot conclude that one (RP or EBRT) is superior to the other.

The impact of newer imaging modalities, like mpMRI, is yet unclear. This is almost not (yet) reported in trials and MRI standardization for local staging is not so old, which results in studies with only a short follow-up period. The other staging imaging modalities have no place yet. Excluding nonmpMRI studies would not leave many papers to discuss, while the purpose of a systematic review is 
to show the entire state of knowledge and not only focus on the most recent data. However, since this is a highly evolving and interesting domain, we added a small section on modern imaging to the text. 


\section{Take home message}

High-risk and locally advanced PCa patients are likely to undergo a multimodality treatment. Patients should be at all-time fully informed about all available options and the likelihood of a multimodal approach including the potential side effects of both local and systemic treatment.

For high-risk localized and locally advanced PCa, both RP as part as multimodal therapy and EBRT + long-term ADT can be recommended as primary treatment.

For high-risk localized PCa, also EBRT + BT can be offered, despite a less favourable toxicity profile. In selected high-risk PCa patients, a shorter duration of ADT might be considered.

Until the results of the SPCG15 trial are known, the optimal local treatment remains a matter of debate. 
Click here to access/download Supplementary file PUBL_Supplementary material 20191104_FINAL_EAU_ASCO.doc 
Your MS Word document "eururoauthorshipform_LM_Intermediate.doc" cannot be opened or processed. Please see the list of common problems and suggested resolutions below.

Common Problems When Creating a PDF from Microsoft Word Documents

When you open your document in MS Word, an alert may appear. This message may relate to margins or document size. You will need to find the piece of your Word document that is causing the problem. Selectively remove various pieces of the file, saving the modified file with a temporary file name. Then try to open the modified file. Repeat this process until the alert no longer appears when you open the document.

Embedded Macros

Your submission file should not contain macros. If it does, an alert may appear when you open your document (this alert prevents EM from automatically converting your Word document into the PDF that Editors and Reviewers will use). You must remove these macros from your Word document.

Read-Only and Password-Protected Files

EM cannot process read-only or password-protected submission files. If your file is read-only or password-protected and you receive an error, please disable the document protection, save, and re-submit the file.

Corrupted Tables

Your document may contain a table that cannot be rendered correctly. This will be indicated by an alert. Correct the content of the table causing the problem so that the alert no longer appears.

Older MS Word files

EM supports files in MS Word 2000 and older versions. If you are using a more recent version of MS Word, try saving your Word document in the more recent format and resubmit to EM.

Other Problems

If you can get your Word document to open with no alert messages appearing and you have submitted it in a current MS Word format, and you still see an error message in your PDF file (where the Word document should be appearing), please contact the publication via the 'Contact Us' link on the EM Navigation Bar.' You will need to reformat your Word document and then re-submit it. 